\title{
PROPUESTA PARA LA IMPLEMENTACIÓN DE UN PLAN DE CARRERA ENFOCADA EN LOS EMPLEADOS CLAVE DE ACKERMANN BEAUMONT COLOMBIA S.A.S
}

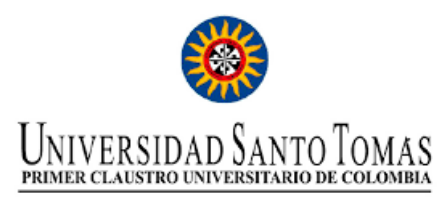

Ana María Forero Rojas

UNIVERSIDAD SANTO TOMAS

FACULTAD DE CIENCIAS ECONÓMICAS Y ADMINISTRATIVAS

PROGRAMA DE AMINISTRACIÓN DE EMPRESAS

BOGOTÁ

2018 
PROPUESTA PARA LA IMPLEMENTACIÓN DE UN PLAN DE CARRERA ENFOCADA EN LOS EMPLEADOS CLAVE DE ACKERMANN BEAUMONT COLOMBIA S.A.S

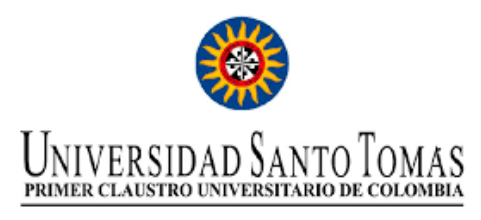

Ana María Forero Rojas

Cód. 2134633

Trabajo de grado para obtener el título de Administradora de Empresas

Director de trabajo de grado:

Miller Rivera Lozano

UNIVERSIDAD SANTO TOMAS FACULTAD DE CIENCIAS ECONÓMICAS Y ADMINISTRATIVAS

PROGRAMA DE AMINISTRACIÓN DE EMPRESAS

BOGOTÁ

2018 


\section{Titulo}

Propuesta de un plan de carrera enfocada en los empleados clave de Ackermann Beaumont Colombia S.A.S. 
Tabla de contenido

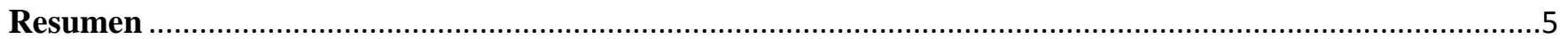

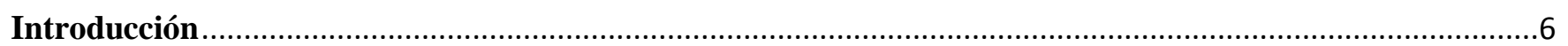

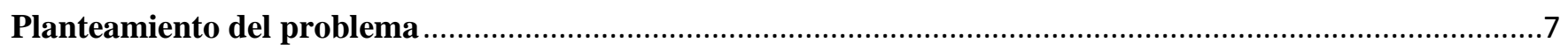

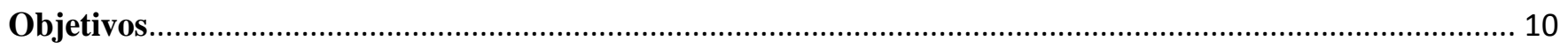

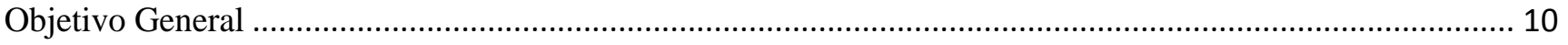

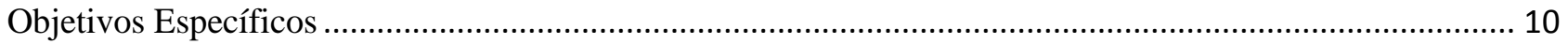

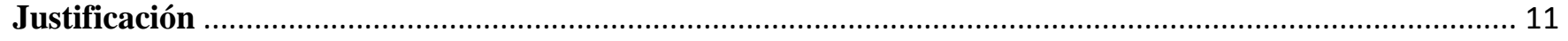

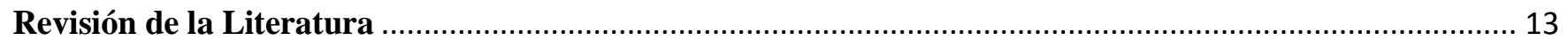

Concepto de Posiciones clave - High Potencial dentro de una compañía ..................................................... 16

Beneficios de la implementación del plan de carrera ............................................................................. 18

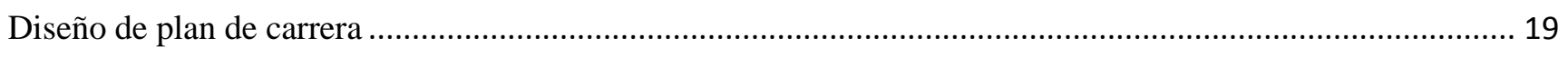

Competencias necesarias para cumplir con los objetivos de la compañía...................................................... 24

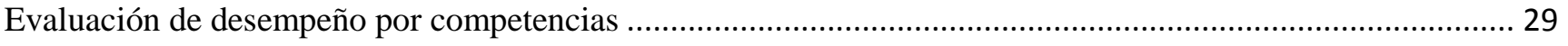

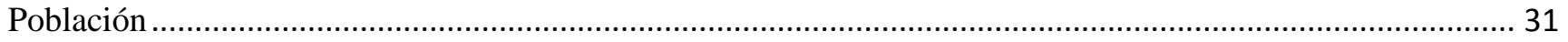

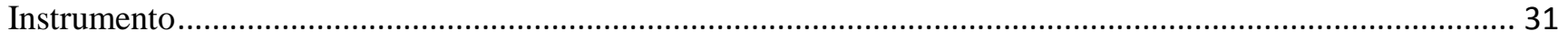

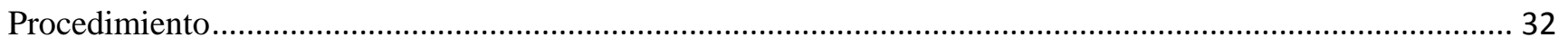

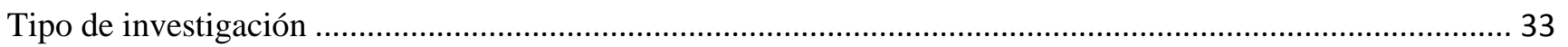

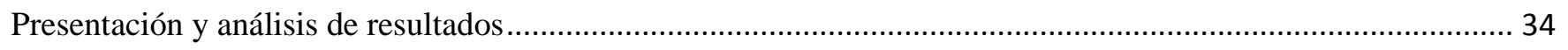

Resultados obtenidos en la evaluación de desempeño para identificar las personas clave en la compañía ........ 35

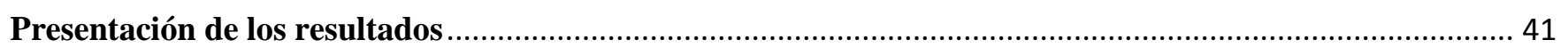

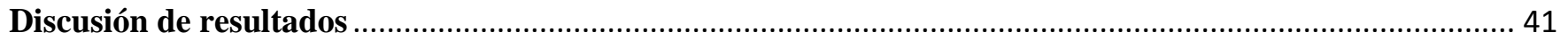

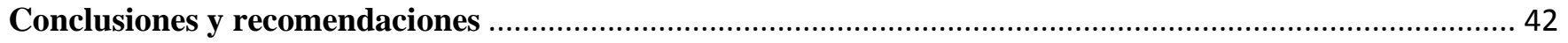

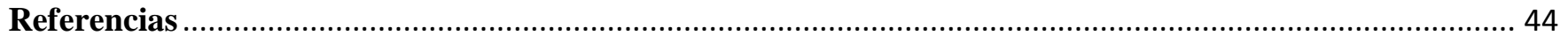

Anexos

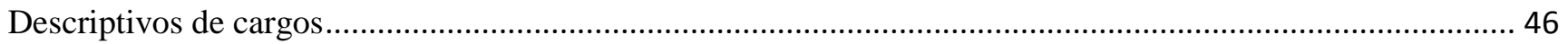

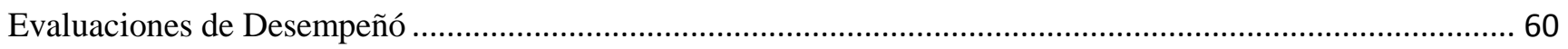

MODELO PLAN DE DESARROLLO PERSONA CLAVE - Directora de operaciones................................. 73

\section{Contenido de tablas}

Tabla 1. Porcentajes evaluación de desempeño por competencias para los asistentes de

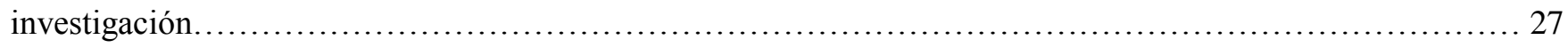


Tabla 2. Porcentaje Total ponderado Evaluación de Desempeñó por competencias Asistentes de investigación. 28

Tabla 3. Porcentajes evaluación de Desempeñó por competencias Consultor Semi Senior. 29

Tabla 4. Porcentajes evaluación de Desempeñó por competencias directores. 30

Tabla 5. Porcentajes Total ponderado Evaluación de Desempeñó por competencias directores. 31

Tabla 6. Porcentajes Total ponderado Evaluación de Desempeñó por competencias Personas claves.... .32

\section{Contenido de figuras}

Figura 1. Carrera Ackermann Beaumont Colombia

S.A.S. 15

Figura 2. Plan de carrera "Paso a paso" 21

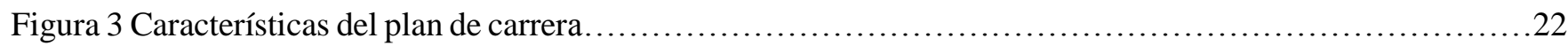

Figura 4Pasos para diseñar un plan de carrera de personas clave .24

Figura 5 comparativa de Evaluación de desempeño por competencias para los asistentes de investigación

Figura 6. de porcentajes Total Ponderado evaluación de desempeño por competencias asistentes de investigación

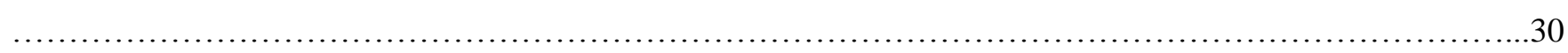

Figura 7 porcentajes evaluación de desempeño por competencias Consultor Semi Senior......................31

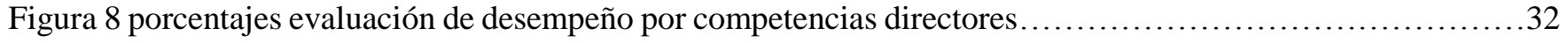

Figura 9 porcentajes Total Ponderado evaluación de desempeño por competencias directores.... 


\title{
Resumen
}

El presente trabajo buscar proponer un plan de carrera de personas claves, es decir, empleados con un alto nivel de potencial que laboran en Ackermann Beaumont Colombia S.A.S., compañía multinacional de búsqueda y selección de Altos Ejecutivos. En consecuencia, la investigación se centra en el personal de la compañía para identificar las personas claves que allí trabajan los cuales deben hacer parte del programa desarrollo de plan de carrera; a partir de los resultados que se obtendrán se pretende proponer un plan de carrera para dichas posiciones, por último, se resalta la definición del tema en desarrollo, el fundamento de fuentes bibliográficas, la importancia del desarrollo de personas claves dentro de la compañía.

Palabras claves: Personas clave, plan de carrera, programa desarrollo de plan de carrera.

\begin{abstract}
The present work focuses on a proposal for the preparation of a career plan for Key People, that is, employees with a high level of potential who work at Ackermann Beaumont Colombia S.A.S., a multinational search and selection company for Senior Executives. Consequently, the research focuses on the company's employees to identify the key people who work there who must be part of the career plan development program; From the results that will be obtained, it is intended to propose a career plan for these positions, finally, the definition of the subject in development, the foundation of bibliographic sources, the importance of the development of key persons within the company is highlighted.
\end{abstract}

Keywords: Key people, career plan, career plan development program 


\section{Introducción}

La necesidad actual de proponer un plan de desarrollo de carrera para empleados claves surge de la necesidad de evitar que los empleados con talento se marchen de la organización, la necesidad de

desarrollo de las personas que hacen parte de la compañía y la búsqueda de mejora de procesos y cumplimiento de objetivos organizacionales. (Gan \& Berbel, 2007, pág. 351). La presente investigación se realiza con la intención de identificar las personas clave de Ackermann Beaumont Colombia S.A.S. con el fin de incluirlas en un plan de desarrollo de carrera que permita potencializar sus competencias, establecer una línea de progreso y aumentar su motivación.

Por lo anterior el objeto de estudio de esta investigación son las personas del área de operaciones y desarrollo de nuevos negocios de la compañía, de esta manera todo el planteamiento y desarrollo de esta investigación permite que se generen varios interrogantes e hipótesis a las que se pretende dar respuesta a través de la revisión bibliográfica y la aplicación de instrumentos, permitiendo de esta manera identificar el personal con alto potencial.

Así, el sentido final de esta monografía es aportar información relevante para futuras investigaciones relacionadas con el plan de Carrera enfocada a los High Potential; aunque ha sido un tema abordado por diferentes autores, es importante aterrizarlos a la redilad de una compañía de servicios. 


\section{Planteamiento del problema}

Ackermann Beaumont Colombia S.A.S., pertenece al sector servicios el cual incluye todas aquellas actividades que no producen una mercancía en sí, pero que son necesarias para el funcionamiento de la economía.

En el primer trimestre del año 2017 la economía colombiana creció 1,1\%. El sector de servicios sociales, comunales y personales se destacó por un crecimiento anual del 2,2\%. (DANE, 2017), este sector cuenta con sub sectores, uno de ellos, el de Servicios Profesionales. Este sub sector ha venido mostrando un comportamiento dinámico, como lo describe la investigación realizada por Procolombia, la cual proyecta que el sector Outsourcing crecerá entre 2,9\% y 9,5\% a lo largo de los próximos 3 años. (Procolombia, 2015)

Ackermann Beaumont Colombia S.A.S. es una compañía Multinacional especializada en búsqueda y selección de altos directivos y profesionales cualificados, y en consultoría de recursos humanos. La compañía nace en el año 2009 con el propósito de convertirse en un proveedor global de servicios de Recursos Humanos de referencia para los clientes. Cuenta con oficinas propias en

España, México, Colombia, Panamá, Brasil, Chile, Perú y Miami. Llegó a Bogotá, Colombia a inicios del año 2010 sus oficinas están ubicadas en el World Trade Center, Torre C, oficina 718. Ackermann Beaumont Colombia S.A.S. es una firma de referencia y trayectoria en su Core de negocio. El equipo de Ackermann Beaumont en Colombia está compuesto por 8 empleados (una 
asistente administrativa, dos investigadoras de mercado, una consultora semi senior dos directores y

el Gerente de País).

Frente a las oportunidades de crecimiento evidenciadas por la compañía, se ha hecho latente la necesidad de facilitar a los empleados actuales el desarrollo de competencias que soporten la ejecución de estrategias dirigidas a fortalecer su presencia en los mercados actuales y en los nuevos a los cuales se pretende llegar con los servicios que conforman el portafolio empresarial ofrecido.

Durante los dos últimos años algunos de los empleados con mayor potencial se han retirado indicando como factor principal para tomar la decisión la falta de un plan de carrera que permita desarrollar y potencializar su talento, comentaron también que las compañías de las que van a hacer parte les ofrecen un plan de carrera y reconocimiento a su trabajo.

Pese a que la compañía identifica en el equipo de trabajo un recurso valioso para el desarrollo de su quehacer misional, no se han adelantado ni desarrollado por parte de la empresa, propuestas a través de las cuales se entregue a los empleados herramientas y métodos que potencien su desarrollo personal y profesional en la compañía, principalmente por el poco presupuesto establecido para este proceso. La compañía ha decidido iniciar evaluando a sus empleados para identificar quienes tiene un mayor potencial y son claves dentro de la organización, para así incluirlos en un plan de desarrollo de carrera enfocado a personas claves, este será una prueba piloto que con el tiempo permitirá abrir las posibilidades e incluir al resto de empleados en planes de desarrollo. 
Frente a las expectativas mencionadas el presente proyecto pretende dar respuesta a la pregunta Pregunta de investigación

¿Cuál es la importancia de la implementación de un plan de desarrollo de carrera enfocado en personas claves de Ackermann Beaumont Colombia S.A.S.? 


\section{Objetivos}

Objetivo General

Elaborar propuesta de plan de carrera para las personas clave - High Potential en Ackermann Beaumont Colombia S.A.S.

Objetivos Específicos

- Identificar las personas clave de la organización por medio de una evaluación de desempeño por competencias.

- Diseñar un plan de carrera individual para las personas clave de Ackermann Beaumont

Colombia S.A.S. 


\section{Justificación}

La presente investigación permite identificar una problemática constante en las organizaciones, como lo es la falta de un plan de carrera para sus colaboradores. A menudo los empleados se encuentran desmotivados o en una zona de confort en su rol actual, por esta razón no generan nuevas ideas, su productividad se ve afectada y por consiguiente los resultados de la compañía desmejoran.

La finalidad de un programa de desarrollo de carrera es lograr integrar las metas de los empleados con los objetivos de la organización (Bohlander \& Scott Snell, Administración de Recursos Humanos, 2013, pág. 225). Permite también, optimizar las estructuras organizacionales

y la compañía será más atractiva en el mercado. De esta manera, es un gran reto para las compañías el preservar y potencializar el capital intelectual de sus colaboradores, permitiendo que las personas se sientan una participante clave dentro de la organización, no le temerá a nuevos retos y se verá proyectado en diferentes cargos a largo plazo.

En las organizaciones empresariales el capital humano es un activo de gran significado que adquiere relevancia al ser los individuos quienes direccionan, gestionan y hacen posible la ejecución del que hacer misional de las compañías. Frente a este reto, es indispensable que las

personas desarrollen capacidades que les permitan entregar alternativas de solución a las diferentes situaciones a las cuales deben responder. Es necesario que cada persona con ayuda de la organización identifique sus puntos fuertes y débiles en la elaboración de planes de acción 
encaminados a crecer acorde con las expectativas del negocio para la competitividad empresarial. Esta investigación proporcionará el material suficiente para dar explicación del porque es importante su implementación en Ackermann Beaumont Colombia S.A.S. con un programa de desarrollo de carrera que entregue una visión global del negocio al empleado, siendo así un apoyo en la toma de decisiones, manejo de equipos, para asumir responsabilidades y compromiso; al tener una ruta clara tendrá exposición con diferentes áreas y podrá entender sus opciones de carrera a seguir.

Ackermann Beaumont Colombia S.A.S., tiene talentos interesantes por desarrollar, así lo ha mencionado el Gerente General, sin embargo, no se ha autorizado gran presupuesto para la ejecución de este proceso, por tal motivo el Gerente General quiere realizar una evaluación que permita identificar los empleados clave de la compañía, con mayor potencial para desarrollar. Para Ackermann Beaumont Colombia un factor primordial es la adaptabilidad de la persona al cargo, respecto a sus competencias duras (técnicas) y blandas (personalidad) dado que sus descriptivos de cargo se realizaron en función de encontrar al talento que cumpla con él mismo.

Con esta investigación se pretende identificar los perfiles potenciales existentes en la organización por medio de la aplicación de una evaluación por competencias. 


\section{Revisión de la Literatura}

El desarrollo de carrera es un enfoque formal el cual establece metas de carrera para el ejecutivo e identifica los medios para alcanzarlas. (Mondy \& Robert M. Noe , 2006, pág. 244). Es de suma importancia para las organizaciones establecer un plan de carrera para sus colaboradores ya que permite tener personal calificado y con la experiencia necesaria para ocupar diferentes cargos en las compañías. Este tipo de políticas dan oportunidad a una mejora de procesos internos, externos y el cumplimiento de objetivos organizacionales ya que los colaboradores están preparados para asumir nuevas posiciones y dar valor a los procesos y cambios que se puedan presentar.

Dar el apoyo a los empleados a crecer y trabajar para desarrollar sus habilidades es un enfoque estratégico y proactivo para retener el talento. Para una correcta implementación de estos programas es necesario trabajar de la mano de la Gerencia General, el área de recursos humanos, el jefe directo de la posición de la persona que iniciara su plan de carrera y por supuesto el empleado, es necesaria la intervención de estos cargos ya que la Gerencia General dará el aval y directrices para establecer políticas de desarrollo, el área de recursos humanos compartirá la información y métodos para lograrlo y el jefe de la posición será el apoyo constante en la gestión diaria, los jefes de la posición pueden identificar las fortalezas y áreas de mejora y así dar retroalimentación de manera constante. 
KPMG firma multinacional que brindan servicios de Auditoría, Impuestos y Asesoría a las áreas transversales de las compañías (KPMG, s.f.) por medio de su Centro de Excelencia realizó una encuesta "War for Talent - Time to Change" (Robert, 2014) a 335 de los principales directores de empresas en 47 países, evidenciando la importancia de un plan de carrera orientado en el desarrollo de competencias de los empleados de las compañías y como el apoyo de la Alta Dirección resulta fundamental para el éxito del proceso como para el cumplimiento del plan estratégico de la organización, dado a lo escaso que es el recurso humano y la guerra en el mercado para conseguir ejecutivos con el potencial idóneo cada vez resulta más difícil, lo anterior demuestra la importancia de hacer una apuesta por el personal interno de la organización.

Actualmente algunas compañías ven esta opción como una inversión para aumentar la rentabilidad de la compañía, razón por la cual aprueban presupuestos más altos para los planes de carrera, aunque el dinero por sí solo no es suficiente para lograr resultados de desarrollo de talento de calidad a menos de que este acompañado de productividad y compromiso, así como una mejor planificación del plan de sucesión. (Crumlish, 2016). El presupuesto dado no es suficiente para crear y llevar a cabo dichos planes de carrera dado que la organización inicialmente debe compartir información detallada del plan de carrera con el empleado para entender el interés de seguir en la compañía y por la misma línea en la que ha trabajado, esto con el fin de realizar un plan exitoso que sea viable e interesante para el empleado. 
Compañías como PepsiCo, compañía multinacional del sector de alimentación y bebidas, está presente en más de 200 países y 168.000 empleados (PepsiCo Colombia, 2007), es un empleador reconocido por su enfoque en el capital humano, uno de sus principales objetivos es tener los mejores profesionales del mercado y una vez están dentro garantizar su crecimiento y desarrollo, esto como estrategia de éxito empresarial. Por tanto, PepsiCo ofrece a sus empleados herramientas puntuales para gestionar su proceso, específicamente la evaluación de desempeño, planificación de carrera, estudio $360^{\circ}$ y encuesta de clima organizacional. Del mismo modo Kimberly Clark, multinacional de sector higiene y salud, con marcas reconocidas como Huggies, Kotex, Kleenex y Scott (Kimberly Clark, 2016); tiene una estrategia mundial basada en Recursos Humanos, conviene destacar que se creó un área denominada Global Performance Management, la cual trabaja en pro de que todos los subsistemas del área sean un factor fundamental y estratégico en la toma de decisiones, siendo el plan de gestión por competencias y los planes de desarrollo de carrera una herramienta primordial para alcanzar sus metas.

Uno de los objetivos del plan de carrera es la formación de las personas que hacen parte de una compañía, para que sus empleados logren asumir nuevos retos y responsabilidades en el momento que sea establecido por el mismo. Dentro del proceso de desarrollo los empleados van dando un siguiente paso hacia su ruta de crecimiento, el cual será dado al desarrollar conocimientos, competencias y experiencia en cada posición. El plan de carrera se ve potencializado cuando los jefes de la posición ejercen un rol activo y se involucran dándole apoyo a sus colaboradores. 
Es posible evidenciar diferentes rutas de carrera, los tres determinados por el potencial y evaluación que ha logrado el empleado durante su carrera profesional son:

- Promociones: Es un cambio vertical a un nivel jerárquico superior, exige mayores habilidades y responsabilidades, por lo general las promociones traen consigo un aumento salarial.

- Transferencias: Movimiento horizontal, es un paso previo a la promoción, es un cambio donde las responsabilidades y habilidades son las mismas, pero se desarrollan en otra área de la compañía, o incluso otra ciudad, por lo general no generan un aumento salarial. Si algo tienen en común es la adaptabilidad al nuevo cargo, nuevo equipo y ambiente.

Concepto de Posiciones clave - High Potencial dentro de una compañía

Las personas clave en términos de plan de carrera hace referencia a las personas con mayor potencial quienes son clave para la compañía, tanto por sus tareas y su talento, este grupo de personas se les hace un seguimiento especial. Según (Alles, Construyendo Talento, 2009, pág. 


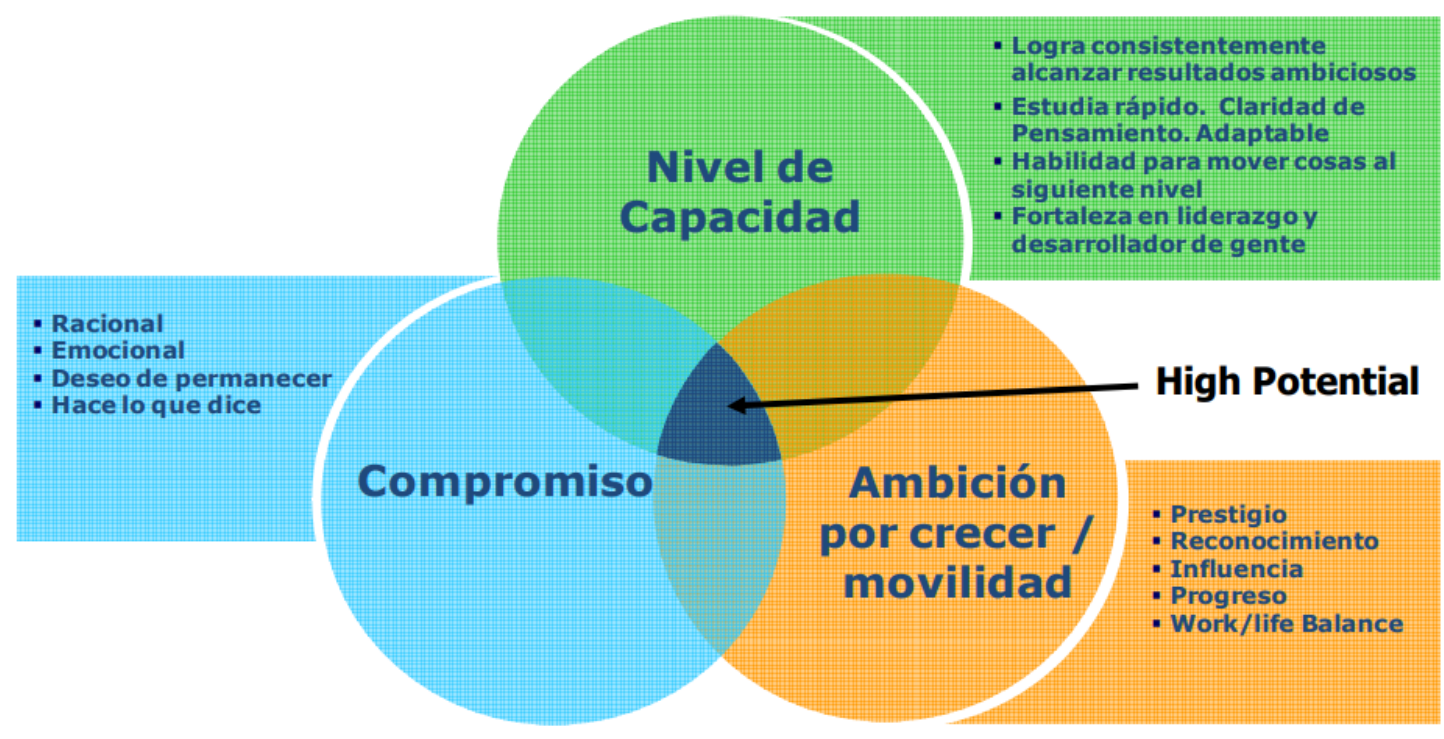

Figura 1. Concepto de High Potencial - Persona Clave

Fuente: Galindo, M. (2010). Charla Deloitte: Gestión del Talento. Chile: Deloitte

Por consiguiente, los High Potencial o personas clave de una organización reúnen una serie de características que le permiten dar valor agregado a su labor,

Douglas Ready y Linda Hill investigadores de la Universidad de Harvard e importantes Ejecutivos definen los High Potential como los empleados con un alto potencial los cuales superan consistente y significativamente a sus grupos de pares en una variedad de entornos y circunstancias. (Ready \& Hill, 2010).

Al interior de cada compañía se identifican empleados con mayor potencial que otros, este tipo de personas a medida que alcanzan un alto nivel de rendimiento y desarrollo de competencias reflejan comportamientos que evidencian la cultura y los valores de sus empresas de manera ejemplar, igualmente, las personas claves en la compañía muestran una gran capacidad para crecer y tener éxito a lo largo de sus carreras dentro de una organización, de manera más rápida y efectiva que sus pares. 
Con la evolución del mercado y las nuevas estructuras organizacionales planas, es menos posible establecer una trayectoria de carrera al interior, por esto debe existir una participación de la dirección y el empleado para preparar las posibles direcciones que puede tomar su carrera al interior de la compañía.

Beneficios de la implementación del plan de carrera

Las compañías que valoran el talento interno son de gran reconocimiento en el mercado, el plan de carrera da satisfacción a los empleados ya que sus competencias, conocimiento y experiencia pueden ser de total ayuda en sus cargos y en su desarrollo profesional, por otro lado si se evalúa desde una perspectiva organizacional, la compañía se verá beneficiada ya que los colaboradores estarán preparados para ocupar un puesto de mayor responsabilidad finalmente esto conlleva a mejorar productividad y cumplimiento de objetivos organizacionales. Asimismo, da la posibilidad al desarrollo de personas claves, dado a la identificación de talento y planificación de carrera de este, también disminuye la tasa de rotación ya que los empleados perciben el interés en el desarrollo de su plan de carrera y genera un vínculo y mayor compromiso con la compañía.

En el siguiente cuadro se evidencia la carrera a seguir en Ackermann Beaumont Colombia S.A.S. 


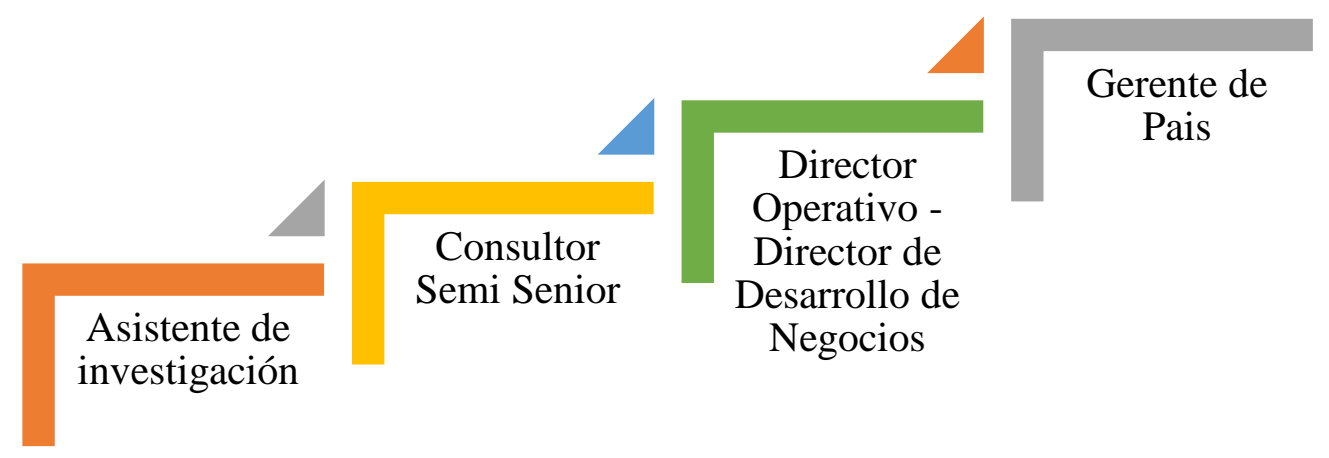

Fuente: Adaptado manual Ackermann Beaumont

Diseño de plan de carrera

El programa de personas clave es un programa de desarrollo de carrera el cual elige un grupo de personas dependiendo de algún parámetro diferencial y estándares de la organización, estas personas son de gran importancia por su potencial de desarrollo y se le ofrecerán oportunidades diferenciales de mejora.

Idealmente el plan de carrera para personas clave no debe estar relacionado con otro plan de carrera como lo podría ser un plan de sucesión, el plan de carrera para personas clave debería ser diseñado para personas que no estén en ningún otro tipo de programa, sin embargo, algunas compañías diseñan el plan de sucesión exclusivamente para los Key people. Es ideal que las personas clave coincidan con los puestos clave.

$\mathrm{Al}$ iniciar este programa es necesario definir los objetivos y el alcance del mismo, adicional a esto al identificar a los participantes del plan de carrera enfocado en personas clave se 
realiza basándose en los casos en los que las personas tengan competencias ya desarrolladas para su posición actual, apoyándose de una evaluación enfocada en competencias ya que el desarrollo estas darán paso al desempeñó superior en otras posiciones, posterior se realizaran planes individuales de formación que permitirán un siguiente paso dentro del plan.

Como primera estancia se debe alinear los objetivos individuales con los de la organización, el sistema de desarrollo debe reflejar las metas y la cultura de la compañía, para lograr esta sinergia los colaboradores deben tener claridad de información corporativa acerca de la planeación estratégica, la misión y visión de esta y entender la ruta de carrera, cómo será la administración de su talento, así como también evaluar e identificar sus habilidades, intereses y conocimientos.

El plan de carrera implica el diseño de un esquema teórico sobre cuál sería la carrera dentro de un área determinada para una persona que ingresa a ella, usualmente desde la posición inicial. Para ello se definen los requisitos para ir pasando de un nivel a otro, instancias que conformarán los pasos a seguir por todos los participantes del programa.

(Alles, Construyendo Talento, 2009, pág. 206)

Los planes de carrera deben realizarse en base a los objetivos organizacionales y las competencias que la compañía considera necesaria en cada posición, para ello se debe evaluar la misión, visión, valores corporativos y el plan de estrategia de crecimiento de compañía, esto para clarificar el rumbo de la empresa y demostrar como el plan de carrera puede aportar al 
cumplimiento de objetivos ya que se necesita desarrollar competencias en los empleados de la organización.

En consecuencia 3 elementos son necesarios a la hora de diseñar el plan de desarrollo se trata de conocimientos, competencias y experiencia, estos tres serán el diferencial para dar el siguiente paso en el plan de carrera, cada uno se debe potencializar hasta alcanzar el nuevo perfil de la siguiente posición dentro del plan. Una vez establecidas dichos elementos se deben crear determinadas acciones y asignar responsables que ayudaran al desarrollo del personal.

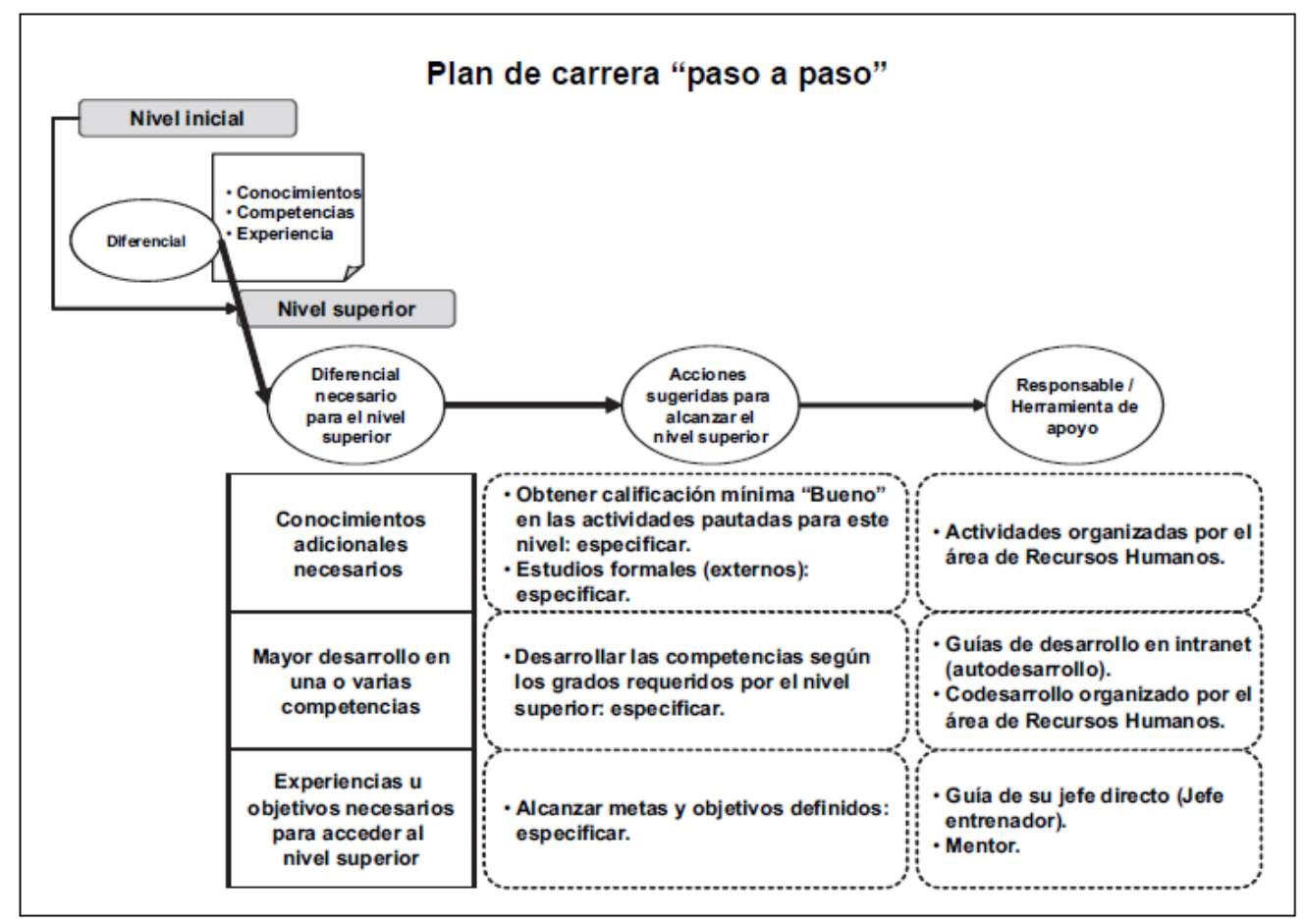

Figura 3. Plan de carrera "paso a paso"

Fuente: Alles, M. (2009). Construyendo talento. Argentina 
Para un correcto desarrollo e implementación del plan, se definen las características del

plan, estas son, el alcance, los objetivos, diseño de la carrera estándar, comunicación amplia y se difunde que no implica ninguna promesa.

\section{Alcance}

- Definición de las areas para la cuales será diseñado el plan de carrera y las areas involucradas.

\section{Objetivos}

- Empleados preparados para ocupar puestos de alta dirección

- Facilita la atraccion de talento a la compañá.

- Retención de talento.

\section{Diseño de carrera estandar}

- Definicion de politicas para dar un paso dentro del plan de carrera.

\section{Comunicación Amplia}

- Tanto los empleados como la Alta Dirección deben estar invlocrados y conocer el plan al detalle.

\section{Difundir que no implica ninguna promesa.}

- No existe una obligacion por parte de la empresa para dar un siguiente cargo al colaborador, si bien es el resultado esperado, la compañía crea el plan estandar y los pasos necesarios para seguir si la sitaución de compañía lo permite.

\section{Figura 4. Características del plan de carrera}

Fuente: Adaptado de Oltra V. (2005). Desarrollo del factor humano. Barcelona: Editorial UOC 
Para cada organización "personas clave” será definido respecto sus parámetros internos, sin embargo, existen aspectos para tener en cuenta al momento de ingresar a una persona al programa, en segundo lugar, se elige el método de evaluación que de mayor visibilidad de los siguientes aspectos. La evaluación de potencial de la persona permite comprobar el nivel del puesto que la persona ocuparía en función del desarrollo de sus competencias, como punto de partido se toma el puesto actual y las capacidades que ha venido demostrando el empleado. (Gan \& Berbel, 2007)

A continuación de evaluar al personal se hace la elección de los participantes, los resultados deben ser cuantitativos para medir las diferentes opciones, con el resultado es posible iniciar con las personas clave y realizar un plan de desarrollo de preferencia individual. Como medida de control pos-establecer e implementar el plan de desarrollo para este grupo de personas es indispensable realizar una evaluación de desempeñó frecuente entre 2 a 3 veces por año, si los resultados de la evaluación no son los esperados se debe realizar un seguimiento continuo y al no llegar a los resultados esperados la persona será desvinculada.

Comunicar a los empleados clave y personas involucradas

Parte del éxito del programa es dar a conocer la existencia de este a los involucrados, ya que implica compromiso reciproco, la compañía realiza una inversión importante en el empleado y el empleado debe esforzarse por cumplir con su plan de carrera. 
Competencias necesarias para cumplir con los objetivos de la compañía

Las competencias son características de personalidad devenidas en comportamientos, con relación a un estándar que a su vez se relaciona con el puesto, es la cantidad necesaria de una determinada característica para desempeñarse exitosamente en

determinado puesto, el desarrollo de competencias es determinante ya que marcan la diferencia y permiten alcanzar la estrategia. (Alles, 5 Pasos para transformar una oficina de personal a un area de Recursos Humanos, 2005, pág. 270)

Como se mencionó anteriormente las competencias deben definirse respecto al perfil de cargo de cada posición, así será posible evaluar y llegar a las personas claves de una organización, al realizar una relación entre resultados y competencias se entenderá el valor generado por el empleado y como realiza la diferencia desde su posición. El identificar cargos claves da una visión del talento interno de la compañía y cómo es posible desarrollarlo para motivarlo y además crear un plan de desarrollo Individual que le permita proyectarse a futuro en la compañía. Las competencias guardan estrecha relación con la estrategia, la cultura y la estructura de una organización, por lo cual pueden ser establecidas aquellas competencias requeridas para el desempeño de un cargo o de una función particular, así como también las que son idóneas en una empresa.

Boyatzis (1982) plantea que una competencia es una característica subyacente en una persona, que está causalmente relacionada con un desempeño bueno o excelente en un puesto de trabajo concreto y en una organización concreta. En términos generales una competencia es la 
capacidad que tiene una persona para desempeñar con éxito una gestión y sobresalir en su desempeño dentro del contexto laboral, a partir de un conjunto de características relacionadas con sus conocimientos, su experiencia, sus habilidades, sus destrezas, sus actitudes, sus motivaciones y su personalidad.

Las competencias se han clasificado de diversas maneras, algunos ejemplos de estas tipologías más comunes son:

- Competencias duras y blandas: Las competencias duras son aquellas que pueden ser aprendidas o adquiridas a través del conocimiento, el entrenamiento o la experiencia. Las competencias blandas son aquellas que hacen parte de habilidades relacionadas con la personalidad, la motivación, las actitudes, entre ellas podemos mencionar competencias de liderazgo, inteligencia emocional, habilidades relacionales, trabajo en equipo.

Las empresas diseñan Modelos de Competencias para la gestión de los procesos en el área de Talento Humano. (Saracho, 2011). El diseño de estos modelos generalmente parte de la estructura organizacional, lo cual da lugar a clasificar las competencias:

- Competencias organizacionales o corporativas: Comunes a todos los cargos y líneas de negocio.

- Competencias Funcionales: Propias de cada área, gerencia o línea de negocio.

- Competencias de familias de cargos con responsabilidades similares.

- Competencias de cargo: Especificas de un cargo o puesto de trabajo. 
Ackermann Beaumont Colombia S.A.S. ha compartido las competencias necesarias al evaluar los distintos cargos de su compañía, las cuales fueron definidas por PDA International, compañía dedicada al diseño de soluciones de Consultoría y gestión de Recursos Humanos apalancadas en la información obtenida a través del PDA Assessment, el cual permite describir y analizar el Perfil Conductual de las personas. (PDA International, s.f.)

PDA ha sido proveedor de Ackermann Beaumont Colombia S.A.S. para el uso de sus pruebas en proyectos con cliente, y para establecer los perfiles de puestos internos tomando principalmente las siguientes competencias.

- Autoconfianza: estar seguro de que se puede realizar un excelente trabajo, cumplir con el objetivo propuesto, y establecer la esencia de cada rol para la organización con el fin de superar problemas, esto incluye establecer nuevos y crecientes retos con actitud de confianza en sus habilidades, puntos de vista y decisiones

- Búsqueda de información: iniciativa, curiosidad por saber más información, sobre temas o personas afines con su función, analizando y respetando la privacidad y confidencialidad de algunos datos que pueden ser de su interés. Se debe ir más allá de realizar las preguntas habituales o requeridas normalmente en el trabajo. Es necesario ahondar para conseguir la información con mayor exactitud, solucionar problemas a través de cuestionamientos.

- Capacidad de Negociación: es la facilidad para concretar negocios imposibles, desarrollar habilidades para generar alianzas y sociedades a largo plazo, con beneficio para las partes. Saber identificar y analizar los intereses de la otra parte, comunicar oportunamente los intereses propios e identificar áreas comunes y llegar acuerdos gana-gana. Se debe manejar las emociones en favor de la negociación. 
- Comunicación: habilidad para generar y transmitir información oportuna, asertiva, y confiable, utilizando el lenguaje verbal y no verbal a las audiencias, para lograr metas y objetivos establecidos.

- Desarrollo de Personas: se requiere un esfuerzo por fomentar el desarrollo, formación e involucramiento de los demás, a partir del análisis de sus necesidades y considerando el contexto organizacional. El hecho no es enviar a las personas a cursos o programas de formación por rutina, sino se debe realizar un esfuerzo mayor por desarrollar a los demás teniendo en cuenta sus necesidades.

Dirección de Gente: Utilizar la autoridad y autonomía que la posición genera de forma efectiva y apropiada, logrando involucrar y comprometer a los demás, para que realicen lo que consideren es adecuado y que va en pro del beneficio de la organización. Es necesario dar pautas en algunos casos y realizar a las personas responsables de su desempeño en la organización.

- Flexibilidad: habilidad para adaptarse y trabajar eficazmente en situaciones, con personas o grupos de trabajo. Quien posea esta habilidad será capaz de apreciar puntos de vista diferentes, acoplando su propio enfoque cuando la situación cambiante lo requiera y fomentando los cambios de la organización o de las responsabilidades a su cargo. - Habilidades Operativas: Habilidad de convertir la estrategia en objetivos específicos, asegurando que la organización o área implemente los procedimientos dirigiendo el riesgo de forma eficaz. Se asigna responsabilidades y autoridad.

- Impacto e Influencia: Intención de incitar, inducir o influir en las demás personas para tenerlas de su lado, conseguir que apoyen sus planes. Ambición de generar impacto en las personas que pueden impactar sus planes, lograr que las demás personas realicen las cosas de la manera que él quiere. 
- Iniciativa: Capacidad de actuar de forma proactiva, genera nuevas búsquedas de oportunidades, busca diferentes soluciones a los problemas.

- Innovación: capacidad de crear algo nuevo, diferente o de vanguardia. Hacer cosas nuevas para mejorar el desempeño propio y de los demás.

- Liderazgo: Habilidad de dirigir grupos o equipos de trabajo dirigidos a un objetivo o meta clara común. Saber guiar a los demás a culminar logros.

- Orientación a Resultados: Es el interés por establecer y lograr metas ambicionas. Se centra en mejorar estándares propios de rendimientos pasados, del desempeño de los demás o lograr algo que ningún otro haya logrado, sin resignarse a los obstáculos y dificultades.

- Orientación al Cliente: Capacidad de analizar, entender y administrar el contacto con los clientes internos, promoviendo una sólida estructura de clientes o asociados. Se debe asegurar que la organización o área lleve a cabo sus compromisos comerciales, mediante el suministro de productos o servicios de excelente calidad.

- Orientación al Mercado: habilidad de entender la forma en el que se desarrollan los negocios en el mercado. Se debe comprender las fuerzas competitivas del mercado, analizar estrategias y tácticas de la competencia para alcanzar posicionamiento competitivo y brindar un valor agregado al consumidor.

- Pensamiento Estratégico: Habilidad de reconocer relaciones entre eventos que no están explícitamente interrelacionados, y elaborar estrategias identificando puntos clave en eventos complejos, se debe aplicar un razonamiento conceptual y creativo.

- Resolución de problemas y toma de decisiones: Habilidad para identificar la información relevante, generar conclusiones, evaluar impacto y toma de decisiones basadas en las diferentes opciones establecidas. 
- Sensibilidad Interpersonal: habilidad para entender las conductas, pensamientos y sentimientos de las personas, expresados verbalmente y no verbalmente. Tener empatía y capacidad de observación.

- Trabajo en Equipo y Cooperación: Trabajar solidariamente con personas de un mismo grupo, interés genuino por lo demás. Gusto por participar y hacer participar a los demás en pro de la construcción de una visión compartida. Quien posea esta habilidad será capaz de elaborar equipos de alto desempeño generando confianza.

- Visión Integral del Negocio: Implica identificar las oportunidades de negocio y desarrollos que agreguen valor al mismo, a través de una orientación al logro de resultados económicos. Tener capacidad de evaluar el impacto de políticas y procedimientos tiene en el negocio, puntos clave de situaciones complejas.

- Vocación por la calidad de Productos y Proyectos: Actuar para alcanzar los más altos estándares de calidad en su mercado. Se proyecta en la evaluación de la información considerando cómo se está ejecutando el trabajo. Insistencia para que los roles y funciones estén sincronizados.

Evaluación de desempeño por competencias

Lo anterior da lugar a realizar una evaluación de desempeño por competencias necesarias para los cargos, para entender su conocimiento práctico y solución de problemas, durante determinado periodo. (Bohlander \& Snell, Administración de Recursos Humanos, 2013, pág. 203) Se debe realizar a las diferentes posiciones existentes, así es como se logra identificar las necesidades y fortalezas, esto será el punto de partida para encaminar los esfuerzos en el desarrollo de carrera. El siguiente paso es identificar las progresiones 
laborales, esto consiste en el desarrollo que tiene el empleado desde su primera posición hacia las demás que requieren mayor conocimiento y habilidades.

Alles (2009) propone una metodología con base a las fichas de evaluación, que en términos generales representa un documento que mide comportamientos y conocimientos basado en las tres características que se ya se han mencionado (competencias, valores y conocimientos) las cuales debe ser diseñadas a la medida de cada empresa según las necesidades de cada cargo y políticas de la empresa.

Algunas compañías multinacionales entre ellas PepsiCo (Fernandez, 2009) realizan una evaluación anual de desempeño por competencias, esta evaluación permite fijar objetivos individuales de desarrollo para cada colaborador según las competencias del cargo. Estos objetivos son definidos en dos categorías: negocio y desarrollo de personas, acordes con los planes de la compañía. Al finalizar el año, al realizar la evaluación el desempeño, los objetivos de desarrollo de personas tienen el mismo peso que los de negocio (50 por ciento-50 por ciento). Esto demuestra la importancia que PepsiCo le da al desarrollo personal y profesional de sus colaboradores.

La necesidad de observar y medir el comportamiento se basa en que, a través de este, los sujetos presentan variedad de competencias que se pueden evidenciar en diversos entornos 
Diseño Metodológico

Población

Ackermann Beaumont Colombia S.A.S. cuenta con 7 empleados, todos administrativos, sin embargo, se ha decidido realizar la investigación con las personas involucradas en la operación de proyectos y área comercial. Dentro del Organigrama los segundos niveles están en dirección del área de Operaciones y área de Desarrollo de nuevos negocios, teniendo en cuenta que uno de los objetivos específicos consiste en identificar las posiciones claves de la organización se realizará la evaluación de desempeño por competencias a los 5 empleados de las áreas anteriormente nombradas, las posiciones a evaluar son dos asistentes de investigación de mercados, un consultor semi senior, el Director de Operaciones y el Director Desarrollo de nuevos negocios).

Instrumento

Para la identificación de los empleados con mayor potencial en la compañía fue utilizada una evaluación de desempeño por competencias, la cual fue elaborada junto con el Gerente General, tomando las competencias del Job Description interno de Ackermann Beaumont Colombia S.A.S. Por ende, se realizó a los 5 empleados del área de Operaciones y Comercial, la cual realizó el jefe de la posición y jefe del área en conjunto, este instrumento identifico la calificación de competencias del cargo actual, el instrumento demostró su desempeñó y que personas son clave para la organización por su alto potencial. La evaluación de desempeñó se compone por dos secciones, la primera enfocado en datos del empleado como nombre del empleado, edad del empleado, reporte directo, periodo evaluado, años de antigüedad y comentarios general, la segunda parte califica las competencias esperadas en relación con la descripción de cargo, de 1 
(Insatisfactoria) a 5 (Excepcional), cada Ítem de calificación corresponde a un porcentaje que en total suma el $100 \%$ del mismo.

Procedimiento

1. El primer paso del proceso fue una reunión con el Gerente General, en esta reunión se trataron temas fundamentales para el desarrollo del proyecto, tales como la definición de la estructura organizacional de la compañía, revisión de Job Description’s y determinación de las competencias a evaluar por cargo, adicional la Gerencia General otorgo la autorización para realizar el estudio con los empleados de la compañía.

2. Investigación acerca de las herramientas necesarias para la elaboración de un plan de desarrollo de carrera de personas claves.

3. Se realizó el diseño de la herramienta Evaluación de desempeño por competencias alineado al Job Description de Ackermann Beaumont Colombia, con el objetivo de identificar por medio de esta los high potential de la organización.

4. Salida de campo, en este paso del proceso se aplicó la evaluación de desempeño por competencias a la población establecida inicialmente en las oficinas de Ackermann 
5. Enseguida se realizó el estudio de resultados del instrumento aplicado de la mano de la Gerencia General.

6. Al finalizar se realizó la valoración final para determinar que posiciones estarían dentro del programa de desarrollo de personas clave, basados en la siguiente tabla.

\begin{tabular}{|c|c|c|c|c|}
\hline Excede las & Alto & Cumple lo & Susceptible de & Deficiente \\
\hline expectativas & & esperado & mejora & \\
\hline $83 \%-100 \%$ & $72 \%-82 \%$ & $61 \%-71 \%$ & $51 \%-60 \%$ & $0 \%-50 \%$ \\
\hline
\end{tabular}

7. Realización de Conclusiones y recomendaciones en base a los resultados obtenidos.

8. Finalmente se elaboró el diseño individual de plan de carrera para los empleados claves.

Tipo de investigación

Esta investigación es de tipo descriptiva comparativa (Tipos de estudio en el enfoque de investigación cuantitativa, pág. 3), ya que describe las diferentes variables en diferentes grupos de personas, posterior se realizó el proceso de tabulación y análisis, este consiste en determinar qué resultados de las variables se presentaron y que relación entre las variables se necesita a fin de dar respuesta al problema planteado. (Metodos de la investigación, s.f., pág. 36) 
Presentación y análisis de resultados

A continuación, se muestra los resultados del estudio obtenido a partir del instrumento evaluación de desempeñó por competencias realizado a 5 posiciones del área de operación y desarrollo de nuevos negocios, el cual permitió identificar las posiciones clave dentro de Ackermann Beuamont Colombia S.A.S. por esta razón estas personas se deben incluir en el desarrollo del plan de carrera de High Potential.

Las competencias usadas en el instrumento fueron tomadas del Job Description compartido por Ackermann Beaumont Colombia, se usaron estas competencias por petición del Gerente General.

Para exponer la información se realizaron tablas y graficas dividas por grupos de posiciones

- Grupo 1: Asistentes de Investigación.

- Grupo 2: Consultor Semi Senior.

- Grupo 3: Directores.

Se evaluó por grupos de cargo como primera estancia para identificar la persona clave en cada grupo, se analizó el desempeñó por competencia, finalmente se obtuvo un total ponderado de la evaluación de desempeñó, el cual dio como resultado el puntaje final de la evaluación de desempeño del cargo. Una vez seleccionado las posiciones con mayor resultado en cada grupo se realizó un análisis de las 3 posiciones con mayor puntaje y desempeño de competencias analizado en la evaluación, dichas posiciones estarán en el programa de desarrollo de talento de personas clave. 
Resultados obtenidos en la evaluación de desempeño para identificar las personas clave en la compañía Evaluación de Desempeñó por competencias asistentes de investigación

\begin{tabular}{|c|c|c|c|c|c|}
\hline Nombre/Competencias & $\begin{array}{c}\text { Búsqueda de } \\
\text { información }\end{array}$ & $\begin{array}{c}\text { Dominio } \\
\text { Segunda } \\
\text { Lengua }\end{array}$ & $\begin{array}{c}\text { Habilidad } \\
\text { Operativa }\end{array}$ & $\begin{array}{c}\text { Orientación a } \\
\text { resultados }\end{array}$ & $\begin{array}{c}\text { Trabajo en } \\
\text { equipo y } \\
\text { cooperación }\end{array}$ \\
\hline $\begin{array}{c}\text { Asistente de } \\
\text { investigación 1 }\end{array}$ & $60 \%$ & $45 \%$ & $60 \%$ & $45 \%$ & $85 \%$ \\
\hline $\begin{array}{c}\text { Asistente de } \\
\text { investigación 2 }\end{array}$ & $95 \%$ & $85 \%$ & $85 \%$ & $60 \%$ & $85 \%$ \\
\hline
\end{tabular}

Tabla 1. Tabla de porcentajes evaluación de desempeño por competencias para los asistentes de investigación 


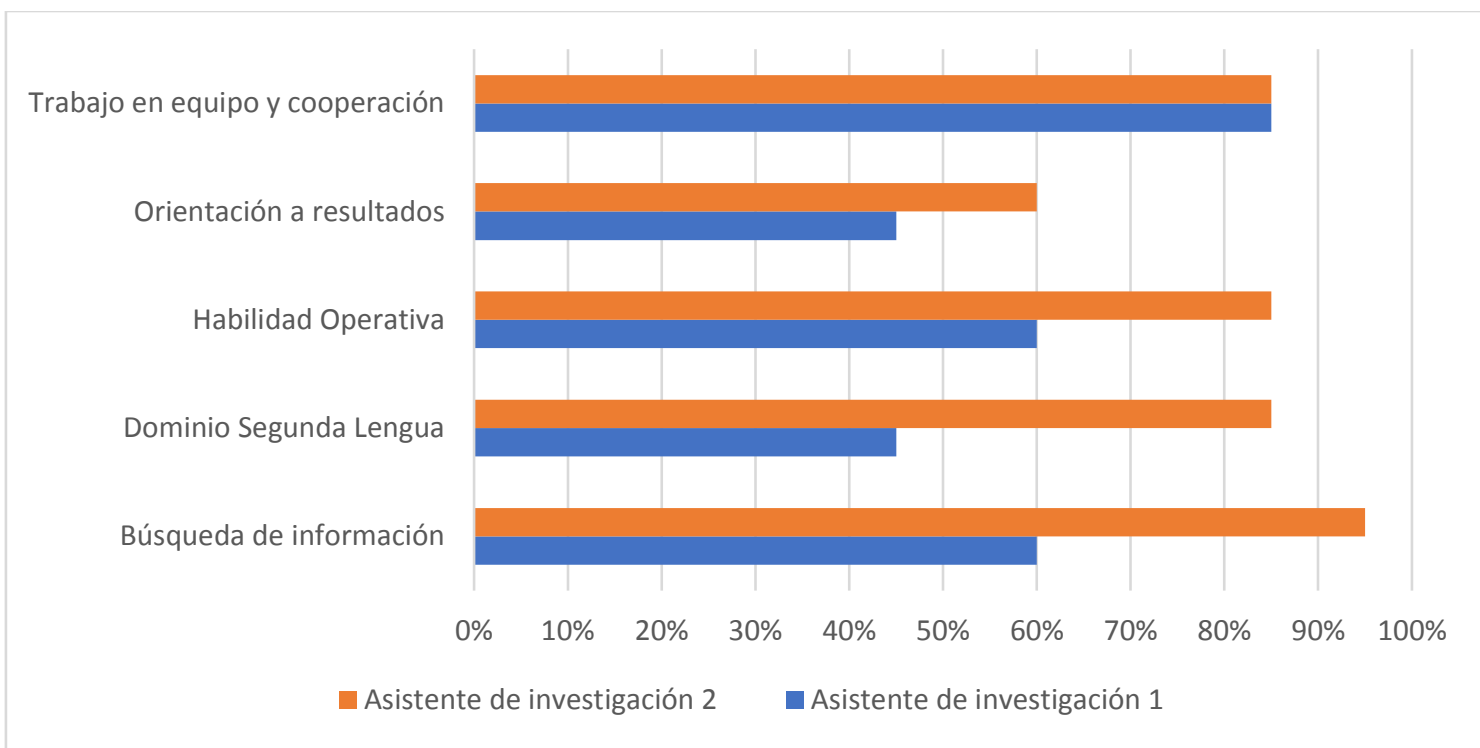

Figura 5. Grafica comparativa de Evaluación de desempeño por competencias para los asistentes de investigación

\begin{tabular}{|c|c|}
\hline Nombre & Total Ponderado \\
\hline Asistente de investigación 1 & $59 \%$ \\
\hline Asistente de investigación 2 & $71 \%$ \\
\hline
\end{tabular}

Tabla 2. Tabla de porcentajes total ponderado Evaluación de Desempeño por competencias Asistentes de investigación

La información anterior muestra el desempeñó para cada competencia de cada asistente de investigación y el total ponderado de los asistentes de investigación, el resultado indica que el empleado con mayor potencial del grupo 1 es el Asistente de investigación 2, durante la evaluación de desempeño por competencias se destacó su trabajo sobresaliente y de calidad, una de sus competencias a desarrollar es la orientación a resultados ya que aún le cuesta cumplir tiempos de entrega, debe desarrollar su sentido de urgencias. Por otro lado, el asistente de investigación 1 debe trabajar en la competencia de búsqueda de información ya que el interés por abrir sus opciones de búsqueda al iniciar un proceso es 
bajo, importante que dedique más tiempo al estudio de una segunda lengua y manejar los momentos de presión, por otra parte se destaca del asistente de investigación 1 su receptividad a la hora de realizarle feedback y su trabajo en equipo.

Evaluación de Desempeñó por competencias Consultor Semi Senior

\begin{tabular}{|l|c|c|c|c|c|c|c|c|c|c|}
\hline $\begin{array}{l}\text { Nombre/ } \\
\text { Competencias }\end{array}$ & Autoconfianza & Comunicación & $\begin{array}{l}\text { Dominio } \\
\text { segunda } \\
\text { lengua }\end{array}$ & Liderazgo & Flexibilidad & $\begin{array}{l}\text { Iniciativa } \\
\text { Orientación }\end{array}$ & $\begin{array}{l}\text { Orientación } \\
\text { al cliente } \\
\text { problemas }\end{array}$ & $\begin{array}{l}\text { Resolución } \\
\text { de }\end{array}$ \\
\hline $\begin{array}{l}\text { Consultor } \\
\text { Semi }\end{array}$ & $85 \%$ & $95 \%$ & $60 \%$ & $85 \%$ & $85 \%$ & $85 \%$ & $85 \%$ & $95 \%$ & $85 \%$ & \\
Senior & & & & & & & \\
\hline
\end{tabular}

Table 3. Tabla de porcentajes evaluación de Desempeñó por competencias Consultor Semi Senior 


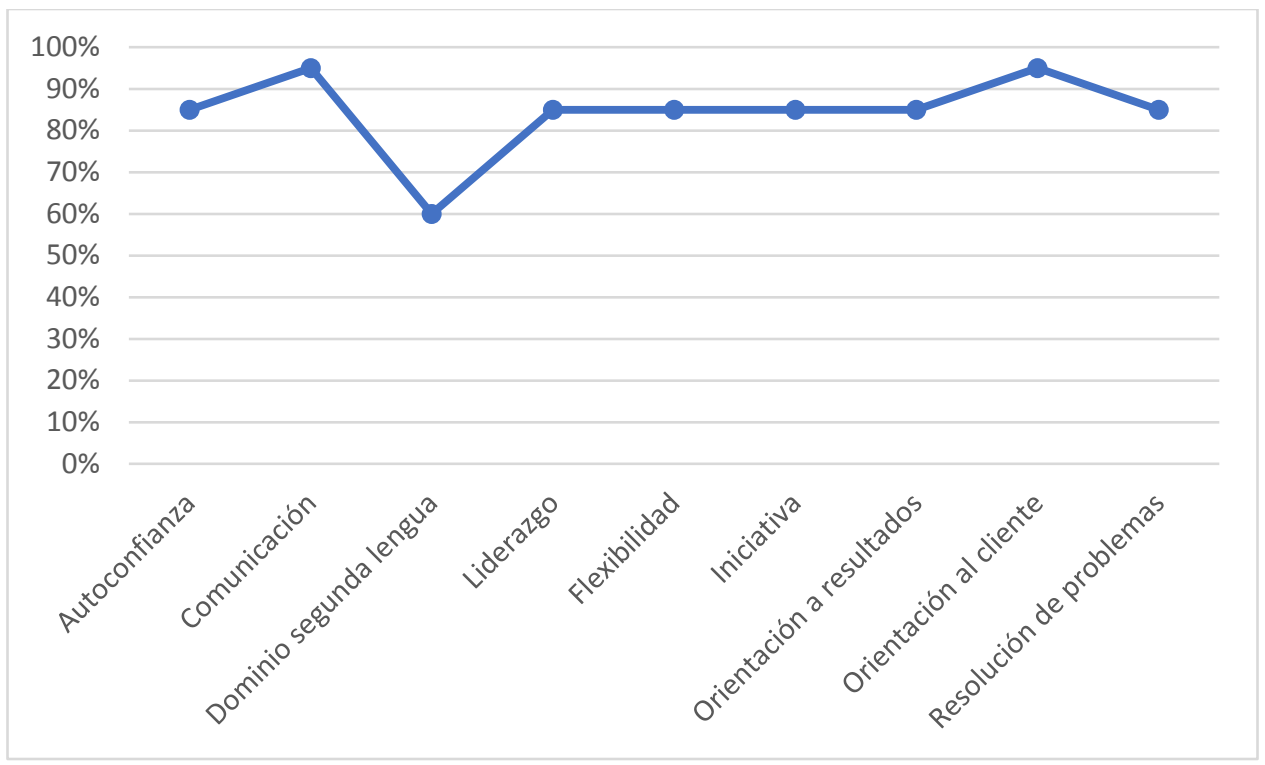

Figura 7. Figura de porcentajes evaluación de desempeño por competencias Consultor Semi Senior

La información de la Consultora Semi Senior fue analizada aparte ya que sus competencias no pueden ser evaluadas frente a otra posición, dado que es la única persona con el cargo dentro de la compañía, sin embargo, su total ponderado respecto a la valoración ponderada de competencias esta en el rango de Excede las expectativas. En la evaluación de desempeño por competencias realizada sus líderes indicaron su alto nivel de potencial, es una persona creativa, con iniciativa que agrega valor a los diferentes procesos de los que es responsable y su trabajo es alta calidad, asimismo, le interesa el desarrollo de su equipo e influye de manera positiva en ellos. Por otro lado, se mencionó la importancia de trabajar en el desarrollo de competencia de dominio de segunda lengua como área de oportunidad, dado a la constante interlocución en ingles que se mantiene con los clientes de la firma. Los evaluadores coincidieron en que su perfil debe estar en el programa de desarrollo de carrera. 
Evaluación de Desempeñó por competencias Directores

\begin{tabular}{|c|c|c|c|c|c|c|c|c|c|c|c|c|c|}
\hline $\begin{array}{l}\text { Empleado/Co } \\
\text { mpetencia }\end{array}$ & $\begin{array}{l}\text { Capacidad de } \\
\text { negociación }\end{array}$ & Comunicación & $\begin{array}{l}\text { Dominio } \\
\text { segunda } \\
\text { lengua }\end{array}$ & Liderazgo & $\begin{array}{l}\text { Desarrollo } \\
\text { de } \\
\text { personas }\end{array}$ & $\begin{array}{l}\text { Dirección } \\
\text { de Gente }\end{array}$ & $\begin{array}{l}\text { Impacto } \\
\text { e } \\
\text { influenc } \\
\text { ia }\end{array}$ & $\begin{array}{l}\text { Orien } \\
\text { tació } \\
n \quad \text { al } \\
\text { client } \\
\text { e }\end{array}$ & $\begin{array}{l}\text { Innov } \\
\text { ación }\end{array}$ & $\begin{array}{l}\text { Orienta } \\
\text { ción al } \\
\text { mercad } \\
\text { o }\end{array}$ & $\begin{array}{l}\text { Pensam } \\
\text { iento } \\
\text { estratég } \\
\text { ico }\end{array}$ & $\begin{array}{l}\text { Sensibil } \\
\text { idad } \\
\text { Interpe } \\
\text { rsonal }\end{array}$ & $\begin{array}{l}\text { Visión } \\
\text { Integral } \\
\text { de negocio }\end{array}$ \\
\hline $\begin{array}{l}\text { Director de } \\
\text { operaciones }\end{array}$ & $95 \%$ & $95 \%$ & $95 \%$ & $95 \%$ & $95 \%$ & $95 \%$ & $95 \%$ & $95 \%$ & $85 \%$ & $85 \%$ & $95 \%$ & $95 \%$ & $85 \%$ \\
\hline $\begin{array}{l}\text { Director } \\
\text { Desarrollo } \\
\text { N.N. }\end{array}$ & $95 \%$ & $85 \%$ & $95 \%$ & $60 \%$ & $45 \%$ & $45 \%$ & $45 \%$ & $95 \%$ & $85 \%$ & $85 \%$ & $95 \%$ & $95 \%$ & $85 \%$ \\
\hline
\end{tabular}

Tabla 4. Tabla de porcentajes evaluación de Desempeño por competencias Directores

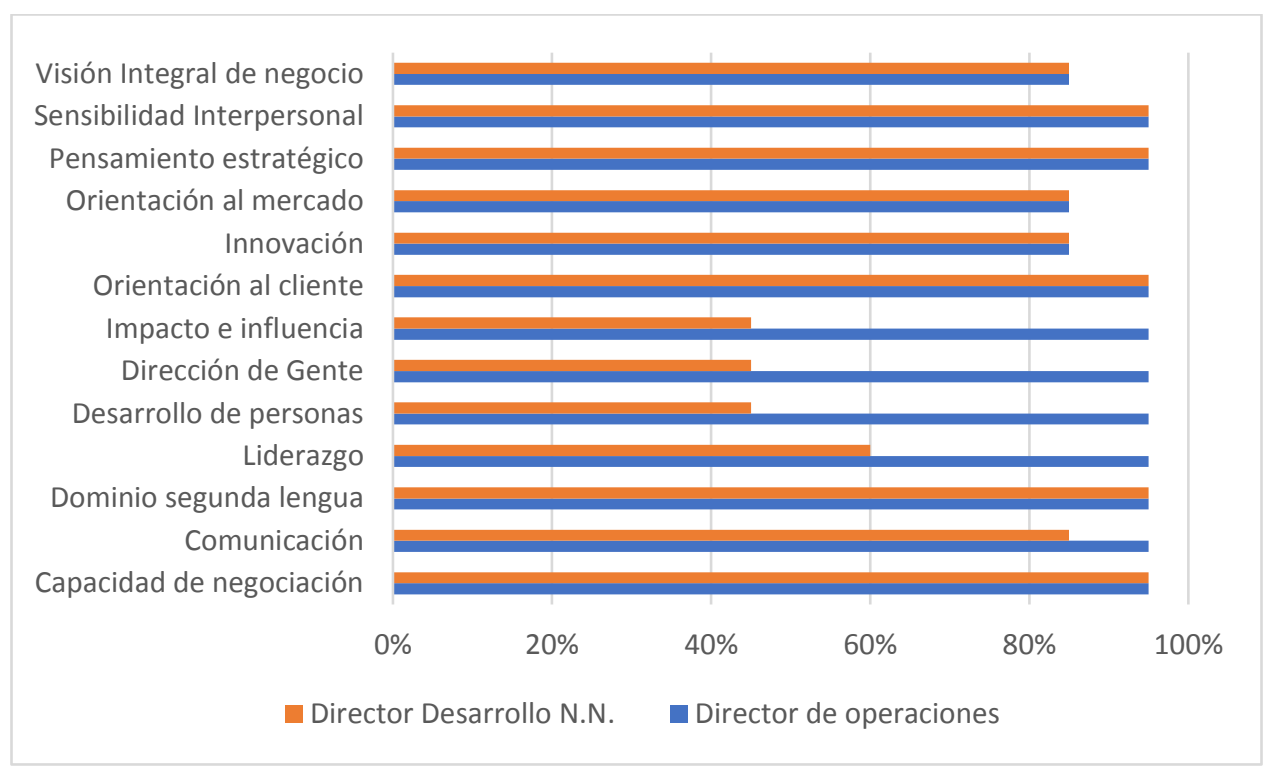

Figura 8. Figura de porcentajes evaluación de desempeño por competencias directores

\begin{tabular}{|c|c|}
\hline Nombre & Total Ponderado \\
\hline Director de Operaciones & $92 \%$ \\
\hline Director Desarrollo Nuevos Negocios & $67 \%$ \\
\hline
\end{tabular}

Tabla 5. Tabla de porcentajes Total ponderado Evaluación de Desempeñó por competencias directores 
La información de los Directores muestra su desempeño en competencias, siendo el Director de operaciones un potencial participante del programa de desarrollo de competencias claves con un ponderado de 92\%, durante su evaluación de desempeño se observó total admiración por parte de su Jefe directo, la considera sin duda un talento que vale la pensar desarrollar, tiene un perfil integral por el manejo de la operación y del cliente que ha tenido a lo largo de su experiencia, este Director tiene el puntaje más alto de todos los grupos, se identifica un área de oportunidad el área comercial, por lo que será importante desarrollar sus habilidades de venta. Por otro lado, el Director de Desarrollo de nuevos negocios, debe reforzar algunas de sus competencias enfocadas al desarrollo de personas, liderazgo antes de lograr entrar al plan de desarrollo de personas claves.

\begin{tabular}{|c|c|}
\hline Nombre & Total Ponderado \\
\hline Director de Operaciones & $92 \%$ \\
\hline Consultor Semi Senior & $85 \%$ \\
\hline
\end{tabular}

Tabla 6. Tabla de porcentajes Total ponderado Evaluación de Desempeñó por competencias Personas claves

Según los resultados de la evaluación de desempeño por competencias de los empleados del área de operaciones y desarrollo de nuevos negocios, las personas que entraran al plan de desarrollo de personas claves son el Director de Operaciones y la Consultora Semi Senior quienes se encuentran en el porcentaje de $83 \%-100 \%$, porcentaje perteneciente a “excede las expectativas". Por sus resultados son Altos potenciales los cuales la compañía está dispuesto a potencializar y desarrollar sus competencias para ocupar futuras posiciones. 


\section{Presentación de los resultados}

El presente estudio permitió identificar a los empleados clave - High Potential al interior de la organización los cuales podrán hacer parte del plan de carrera, esto gracias a la evaluación de desempeño por competencias realizada a cada uno de ellos. Así pues, al evaluar su cargo con las competencias del mismo se pudo observar el desempeño frente a cada una de ellas y entender sus áreas

de oportunidad y fortalezas, posterior se identificó los resultados ponderados más altos que mostró quiénes serían parte del plan. La información detectada también fue útil al momento de realizar el plan de carrera ya que se podrá trabajar sobre aquellas competencias duras y blandas que se deben potencializar o desarrollar, necesarias para dar un siguiente paso en la organización.

\section{Discusión de resultados}

La presente investigación tuvo como función identificar las personas claves dentro de la organización; para llevar a cabo lo anterior, se realizó la medición a través de la aplicación de una evaluación de desempeño por competencias. De los resultados alcanzados en esta investigación, se evidencio la siguiente información.

1. Hay dos posiciones claves dentro de la organización Directora de Operaciones y Consultor Semi Senior. 


\section{Conclusiones y recomendaciones}

Se le recomienda a Ackermann Beaumont Colombia S.A.S. implementar un plan de desarrollo de medidas orientadas a soportar el proceso de cambio de cada una de las personas claves a partir de las competencias identificadas que impactan el desempeño del ejecutivo y la efectividad en su liderazgo. En

consecuencia, para que los empleados clave logren dar un paso dentro de su plan de carrera es importante trabajar sus áreas de desarrollo, con ayuda de apalancadores (características consideradas fortalezas que permiten movilizar y gestionar las áreas de desarrollo) y facilitadores (espacios y ambientes donde el empleado pueda desplegar todo su potencial) de competencias debidamente definidos, y unas acciones de mejora tendientes a desarrollar las brechas identificadas a lo largo del proceso de evaluación.

Las Acciones de mejora deben estar enfocadas en pro de enriquecer tanto su conocimiento técnico como el desarrollo de competencias necesarias según el Job Description lo indique para el siguiente cargo establecido en el plan de carrera.

Por otro lado, para crear la ruta de carrera de los empleados clave debe realizarse una reunión con el jefe del directo, jefe del área y el empleado para establecer que línea debe tomar y con base a eso ejecutar el plan propuesto anteriormente.

En conclusión, de la información obtenida en la presente investigación tanto en la aplicación del instrumento como en la investigación general, se logró dar respuesta al planteamiento principal del trabajo, la importancia de la implementación de un plan de carrera es de suma importancia ya que 
permite tener personal calificado y con la experiencia necesaria para realizar la ruta de carrera establecida por la organización.

La aplicación del instrumento identifico quienes debían hacer parte de un plan de carrera y proporciono la información suficiente para iniciar a trabajar en su plan de desarrollo ya que se logró obtener calificación de cada competencia necesaria para el cargo actual, adicional la Gerencia General identifico la importancia de iniciar a potencializar y desarrollara las personas clave con el finde dar una proyección a futuro en su carrera profesional. 


\section{Referencias}

Alles, M. A. (2005). 5 Pasos para transformar una oficina de personal a un area de Recursos Humanos. Buenos Aires: Ediciones Granica.

Alles, M. A. (2009). Construyendo Talento. Buenos Aires: Ediciones Grainica.

Banco de la Republica. (2015). Sectores Economicos. Obtenido de http://www.banrepcultural.org/blaavirtual/ayudadetareas/economia/sectores_economicos

Bohlander, G., \& Scott Snell. (2013). Administración de Recursos Humanos. Mexico : Cengage Learning Editores.

Bohlander, G., \& Snell, S. (2013). Administración de Recursos Humanos. México: Cengage Lerning Editores.

Crumlish, K. (2016). 3 Business Imperatives for Successful Talent Development. Obtenido de Human Resources Today: http://www.humanresourcestoday.com/talent-development/?open-article-id=5971071\&articletitle=3-business-imperatives-for-successful-talent-development\&blogdomain=visibilitysoftware.com\&blog-title=visibility-software-hr

DANE. (2017). Obtenido de En el primer trimeste de 2017 la economía colombiana creció 1,1\%: http://www.dane.gov.co/files/investigaciones/boletines/pib/cp_PIB_Itrim17_oferta.pdf

Fernandez, J. (Enero de 2009). Una gestión de carrera ejemplar, base del crecimiento de PepsiCo. Obtenido de Gestión de RRHH: http://pdfs.wke.es/0/8/7/7/pd0000030877.pdf

Galindo, M. (2010). Obtenido de Deloitte Web Site: http://oportunidades.deloitte.cl/marketing/RRHH/Gestion_del_Talento.pdf

Gan, F., \& Berbel, G. (2007). Manuel de Recursos Humanos. Barcelona: Centaures del Desert.

Kimberly Clark. (2016). Obtenido de Kimberly Clark Web Site : http://www.kclatamcarreras.com/es/who-weare.aspx

KPMG. (s.f.). Who we are KPMG Linkedin. Obtenido de https://www.linkedin.com/company/kpmg/

Metodos de la investigación. (s.f.). http://files.sld.cu/ginecobs/files/2017/04/manual_metodologia_inv_perez_alejo_final.pdf.

Miralles, O. (2015). Planes de Carrera. Verdades y mitos. Obtenido de http://www.mejorespracticasrrhh.es/planes-de-carrera/

Mondy, R. W., \& Robert M. Noe . (2006). Administración de Recursos Humanos. México: Pearson Educación.

oltra, V., Cúros, P., Rodriguez, J., Teba, R., \& Tejero, J. (2005). En Desarrollo del factor humano (pág. 229). Barcelona: UOC.

PDA International. (s.f.). http://www.pdainternational.net/en-US/PDAAboutUs.aspx.

PepsiCo Colombia. (Sep de 2007). Obtenido de Pepsico Sitio Web: http://www.pepsico.com.co/quienes-somos 
Procolombia. (2015). Obtenido de http://www.inviertaencolombia.com.co/sectores/servicios/tercerizacion-deservicios-bpo.html

Ready, D., \& Hill, L. (2010). Are you a High Potential? Harvard Business Review. Obtenido de Harvard Web Site.

Robert, B. (Junio de 2014). Obtenido de KPMG Sitio Web: https://home.kpmg.com/content/dam/kpmg/pdf/2014/07/war-for-talent.pdf

Rosche, J. (2004). Who's managing your career? Contract Management.

Saracho, J. M. (2011). Talento Organizacional. Santiago de Chile: RIL Editores.

Tipos de estudio en el enfoque de investigación cuantitativa. (s.f.). Obtenido de http://www.redalyc.org/pdf/3587/358741821004.pdf

Tipos de estudio en el enfoque de investigación cuantitativa. (s.f.). http://www.redalyc.org/pdf/3587/358741821004.pdf. 
Anexos

Descriptivos de cargos

\section{Perfil de Puesto: Asistente de investigación}

\begin{tabular}{|c|c|c|c|}
\hline Área: & \multicolumn{3}{|l|}{ Dirección de Operaciones } \\
\hline Cargo Jefe Área: & \multicolumn{3}{|l|}{ Director de Operaciones } \\
\hline \# de personas a cargo & \multicolumn{3}{|l|}{0} \\
\hline Cargo al que reporta: & \multicolumn{3}{|l|}{ Consultor Semi Senior } \\
\hline Rol del cargo: & estratégico $\square$ & $\square$ & soporte \\
\hline
\end{tabular}

1. Misión de Cargo:

Proporcionar al Consultor Semi Senior información esencial para la finalización de la fase de investigación de los esfuerzos de búsqueda.

\section{Responsabilidades del Cargo:}

\section{Responsabilidades}

1. Desarrollar investigación de mercado de posibles empresas para los diferentes sectores y compañías.

2. Apoyo continuo en el desarrollo de estrategias de investigaciones de mercado detalladas, basadas en el uso de bases de datos, búsquedas anteriores, fuentes de información e identificación de compañías prospectos.

3. Realizar entrevistas telefónicas a los posibles candidatos e identificar a través de este si el perfil del candidato se ajusta a los requerimientos del cliente.

4. Realizar entrevistas personales acompañado del Consultor Semi Senior a los diferentes candidatos potenciales.

5. Garantizar la correcta entrega de los documentos a los clientes.

6. Estudio del perfil a buscar entendiendo las necesidades del cliente.

7. Mantener alimentada la base de datos de la empresa, con todos los puntos básicos y necesarios en términos de calidad con el cliente - candidato. 


\section{Requerimientos Educativos y de Formación:}

EDUCACION:

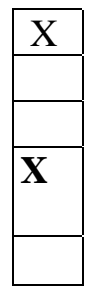

Bachillerato

Tecnologías

Universitario

Postgrados
Estudio técnico posterior a secundaria
DESCRIPCION:

\begin{tabular}{|l|}
\hline Bachiller \\
\hline \\
\hline Administración de empresas, Psicología, Ingeniería \\
Industrial \\
\hline \\
\hline
\end{tabular}

\section{FORMACION:}

HABILIDADES: Impecable presentación personal, alta capacidad de expresión escrita, redacción, alta y facilidad de expresión oral.

EXPERIENCIA: Preferiblemente al menos 1 años en áreas de búsqueda y selección de ejecutivos.

\section{Perfil de Competencias}

\begin{tabular}{|c|c|c|c|c|c|c|}
\hline \multirow{2}{*}{\multicolumn{2}{|c|}{ COMPETENCIAS }} & \multicolumn{5}{|c|}{$\begin{array}{l}\text { PERFIL DE } \\
\text { DESARROLLO }\end{array}$} \\
\hline & & 1 & 2 & 3 & 4 & 5 \\
\hline 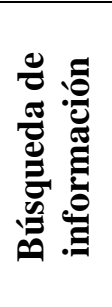 & $\begin{array}{l}\text { iniciativa, curiosidad por saber más información, sobre temas o } \\
\text { personas afines con su función, analizando y respetando la privacidad } \\
\text { y confidencialidad de algunos datos que pueden ser de su interés. Se } \\
\text { debe ir más allá de realizar las preguntas habituales o requeridas } \\
\text { normalmente en el trabajo. Es necesario ahondar para conseguir la } \\
\text { información con mayor exactitud, solucionar problemas a través de } \\
\text { cuestionamientos. }\end{array}$ & & & & & $\mathrm{X}$ \\
\hline 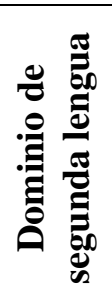 & Capacidad para relacionarse, redactar y leer informes en ingles & & & & $\mathrm{X}$ & \\
\hline نี & $\begin{array}{l}\text { Habilidad para generar y transmitir información oportuna, asertiva, y } \\
\text { confiable, utilizando el lenguaje verbal y no verbal a las audiencias, } \\
\text { para lograr metas y objetivos establecidos. }\end{array}$ & & & & & $\mathrm{X}$ \\
\hline
\end{tabular}




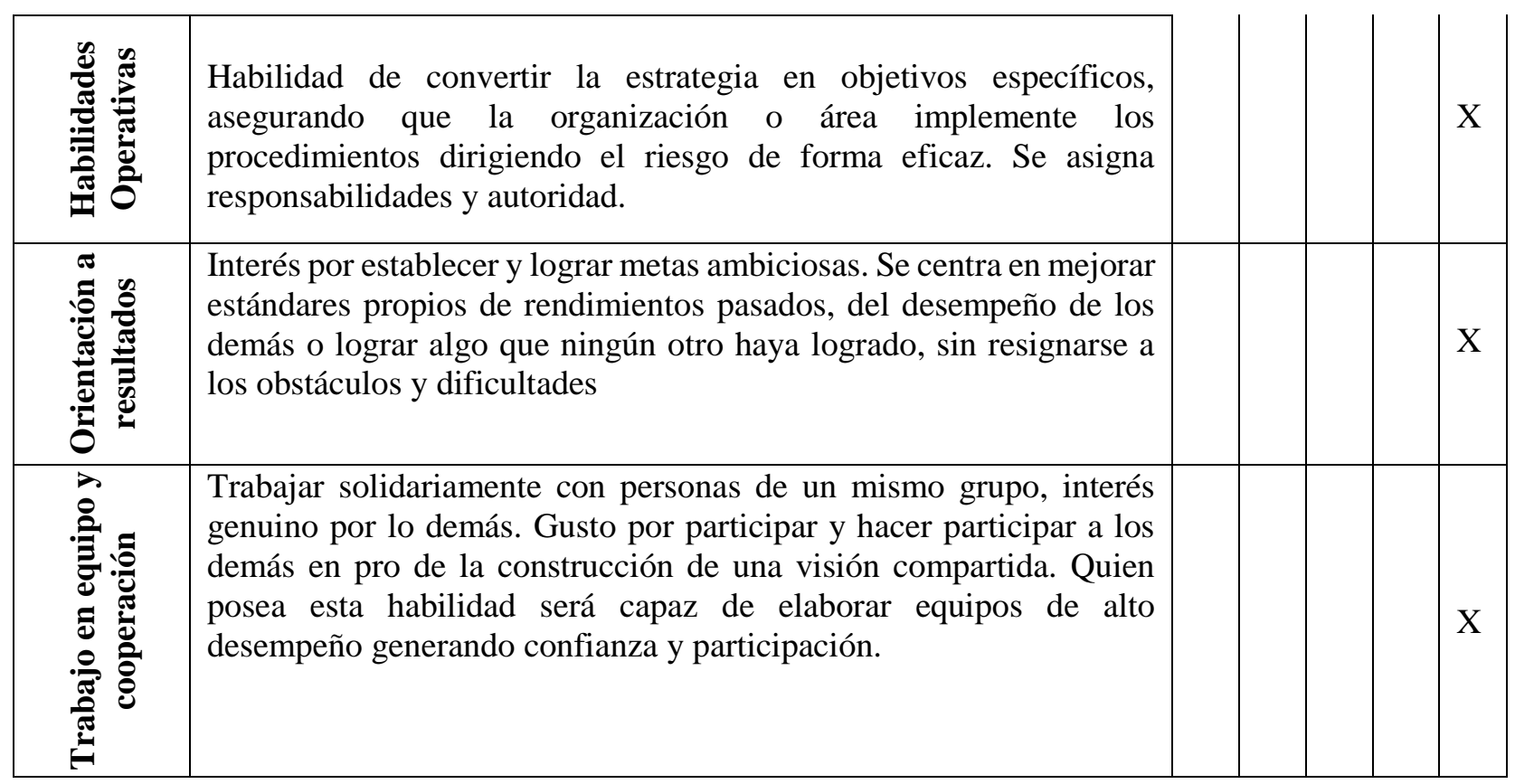




\section{Perfil de Puesto: Consultor Semi Senior}

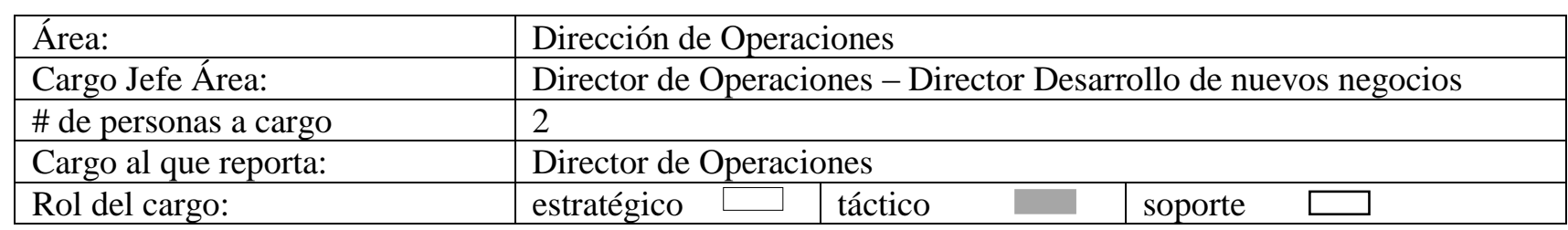

1. Misión de Cargo:

Ejecutar los procesos de consultoría de búsqueda y selección de ejecutivos, manteniendo la relación constante con el cliente.

\section{Responsabilidades del Cargo:}

\section{Responsabilidades}

1. Realizar la ejecución de los procesos de búsqueda, descripción de cargo, estrategia de búsqueda, entrevistas personales, creación de reportes confidenciales, negación de oferta y seguimiento a los ejecutivos colocados

2. Brindar un servicio integral de consultoría en búsqueda y selección de altos ejecutivos.

3. Liderad procesos en Colombia, panamá y otros países de la región

4. Coordinar el trabajo de equipo de investigación de mercados de la empresa compuestos por 2 personas.

5. Mantener relacionamiento con el cliente

\section{Requerimientos Educativos y de Formación:}

\section{EDUCACION:}

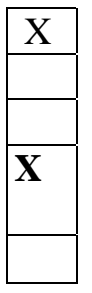

Bachillerato

Tecnologías

Universitario

Postgrados
Estudio técnico posterior a secundaria
DESCRIPCION:

\begin{tabular}{|c|}
\hline Bachiller \\
\hline \\
\hline Administración de empresas, Psicología, Ingeniería \\
Industrial \\
\hline \\
\hline
\end{tabular}

\section{FORMACION:}

HABILIDADES: Impecable presentación personal, alta capacidad de expresión escrita, redacción, alta y facilidad de expresión oral, manejo de clientes.

EXPERIENCIA: Preferiblemente 2 años ejecutando procesos de de búsqueda y selección de ejecutivos, 2 años de experiencia en áreas de investigación de mercados de ejecutivos 


\section{Perfil de Competencias}

\begin{tabular}{|c|c|c|c|c|c|c|}
\hline \multirow{2}{*}{\multicolumn{2}{|c|}{ COMPETENCIAS }} & \multicolumn{5}{|c|}{$\begin{array}{l}\text { PERFIL DE } \\
\text { DESARROLLO }\end{array}$} \\
\hline & & 1 & 2 & 3 & 4 & 5 \\
\hline 胥 & $\begin{array}{l}\text { estar seguro de que se puede realizar un excelente trabajo, cumplir } \\
\text { con el objetivo propuesto, y establecer la esencia de cada rol para la } \\
\text { organización con el fin de superar problemas, esto incluye } \\
\text { establecer nuevos y crecientes retos con actitud de confianza en sus } \\
\text { habilidades, puntos de vista y decisiones }\end{array}$ & & & & & $\mathrm{X}$ \\
\hline 苟 & Capacidad para relacionarse, redactar y leer informes en ingles & & & & & $\mathrm{X}$ \\
\hline 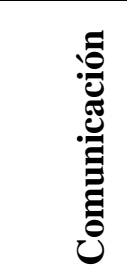 & $\begin{array}{l}\text { Habilidad para generar y transmitir información oportuna, asertiva, y } \\
\text { confiable, utilizando el lenguaje verbal y no verbal a las audiencias, } \\
\text { para lograr metas y objetivos establecidos. }\end{array}$ & & & & & $\mathrm{X}$ \\
\hline 总 & $\begin{array}{l}\text { Habilidad de dirigir grupos o equipos de trabajo dirigidos a un } \\
\text { objetivo o meta clara común. Saber guiar a los demás a culminar } \\
\text { logros. }\end{array}$ & & & & & $\mathrm{X}$ \\
\hline 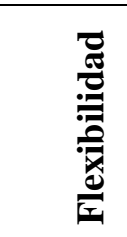 & $\begin{array}{l}\text { Habilidad para adaptarse y trabajar eficazmente en situaciones, con } \\
\text { personas o grupos de trabajo. Quien posea esta habilidad será capaz } \\
\text { de apreciar puntos de vista diferentes, acoplando su propio enfoque } \\
\text { cuando la situación cambiante lo requiera y fomentando los cambios } \\
\text { de la organización o de las responsabilidades a su cargo. }\end{array}$ & & & & & $\mathrm{X}$ \\
\hline 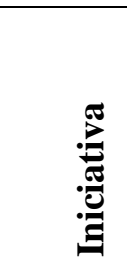 & $\begin{array}{l}\text { capacidad de actuar de forma proactiva, genera nuevas búsquedas de } \\
\text { oportunidades, busca diferentes soluciones a los problemas. }\end{array}$ & & & & & $\mathrm{X}$ \\
\hline
\end{tabular}




\begin{tabular}{|l|l|l|l|l|l|}
\hline & $\begin{array}{l}\text { Interés por establecer y lograr metas ambicionas. Se centra en } \\
\text { mejorar estándares propios de rendimientos pasados, del desempeño } \\
\text { de los demás o lograr algo que ningún otro haya logrado, sin } \\
\text { resignarse a los obstáculos y dificultades. }\end{array}$ & & & & \\
\hline
\end{tabular}




\section{Perfil de Puesto: Director de Operaciones}

\begin{tabular}{|c|c|c|c|}
\hline Área: & \multicolumn{3}{|l|}{ Dirección de Operaciones } \\
\hline Cargo Jefe Área: & \multicolumn{3}{|l|}{ Director de Operaciones } \\
\hline \# de personas a cargo & \multicolumn{3}{|l|}{1} \\
\hline Cargo al que reporta: & \multicolumn{3}{|l|}{ Gerente de País } \\
\hline Rol del cargo: & estratégico & $\square$ & soporte \\
\hline
\end{tabular}

\section{Misión de Cargo:}

Establecer las estrategias e implementar los procesos de consultoría de búsqueda y selección de ejecutivos en primeros, segundos y terceros niveles de la organización.

\section{Responsabilidades del Cargo:}

\section{Responsabilidades}

1. Establecer planeación de los procesos de búsqueda, descripción de cargo, estrategia de búsqueda.

2. Manejar las relaciones de alto nivel con los principales clientes nacionales e internacionales de la firma en Colombia y países de la región.

3. Estrategia de operación anual.

4. Dar seguimiento a la cartera de los clientes asignados.

5. Coordinar el trabajo de equipo de operaciones, compuesto por 1 personas directa y 2 indirectas.

6. Apoyar la contratación de personal de la firma, coordinación y soporte al entrenamiento de todas las nuevas personas contratadas para el área de operaciones.

\section{Requerimientos Educativos y de Formación:}

\section{EDUCACION:}

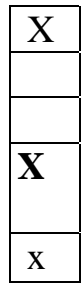

Bachillerato

Tecnologías

Universitario

Postgrados
Estudio técnico posterior a secundaria

\section{DESCRIPCION:}

\begin{tabular}{|l|}
\hline Bachiller \\
\hline \\
\hline Administración de empresas, Psicología, Ingeniería \\
Industrial \\
\hline Especialización en Gerencia del talento humanos \\
\hline
\end{tabular}

\section{FORMACION:}


HABILIDADES: Impecable presentación personal, alta capacidad de expresión escrita, redacción, alta y facilidad de expresión oral, manejo de clientes, habilidad y dominio de la planeación estratégica anual.

EXPERIENCIA: Preferiblemente 2 años Liderando la estrategia de los procesos de búsqueda y selección de ejecutivos, relación a todos los niveles con el cliente, 3 años de experiencia en ejecución de procesos

\section{Perfil de Competencias}

\begin{tabular}{|c|c|c|c|c|c|c|}
\hline \multirow{2}{*}{\multicolumn{2}{|c|}{ COMPETENCIAS }} & \multicolumn{5}{|c|}{$\begin{array}{l}\text { PERFIL DE } \\
\text { DESARROLLO }\end{array}$} \\
\hline & & 1 & 2 & 3 & 4 & 5 \\
\hline 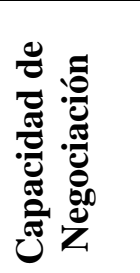 & $\begin{array}{l}\text { Facilidad para concretar negocios imposibles, desarrollar habilidades } \\
\text { para generar alianzas y sociedades a largo plazo, con beneficio para } \\
\text { las partes. Saber identificar y analizar los intereses de la otra parte, } \\
\text { comunicar oportunamente los intereses propios e identificar áreas } \\
\text { comunes y llegar acuerdos gana-gana. Se debe manejar las emociones } \\
\text { en favor de la negociación. }\end{array}$ & & & & & $\mathrm{X}$ \\
\hline 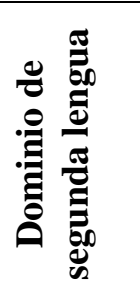 & Capacidad para relacionarse, redactar y leer informes en ingles & & & & & $\mathrm{X}$ \\
\hline ن⿺辶卂 & $\begin{array}{l}\text { Habilidad para generar y transmitir información oportuna, asertiva, y } \\
\text { confiable, utilizando el lenguaje verbal y no verbal a las audiencias, } \\
\text { para lograr metas y objetivos establecidos. }\end{array}$ & & & & & $\mathrm{X}$ \\
\hline 总 & $\begin{array}{l}\text { Habilidad de dirigir grupos o equipos de trabajo dirigidos a un } \\
\text { objetivo o meta clara común. Saber guiar a los demás a culminar } \\
\text { logros. }\end{array}$ & & & & & $\mathrm{X}$ \\
\hline 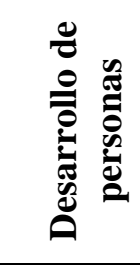 & $\begin{array}{l}\text { Se requiere un esfuerzo por fomentar el desarrollo, formación e } \\
\text { involucramiento de los demás, a partir del análisis de sus necesidades } \\
\text { y considerando el contexto organizacional. El hecho no es enviar a } \\
\text { las personas a cursos o programas de formación por rutina, sino se } \\
\text { debe realizar un esfuerzo mayor por desarrollar a los demás teniendo } \\
\text { en cuenta sus necesidades. }\end{array}$ & & & & & $\mathrm{X}$ \\
\hline
\end{tabular}




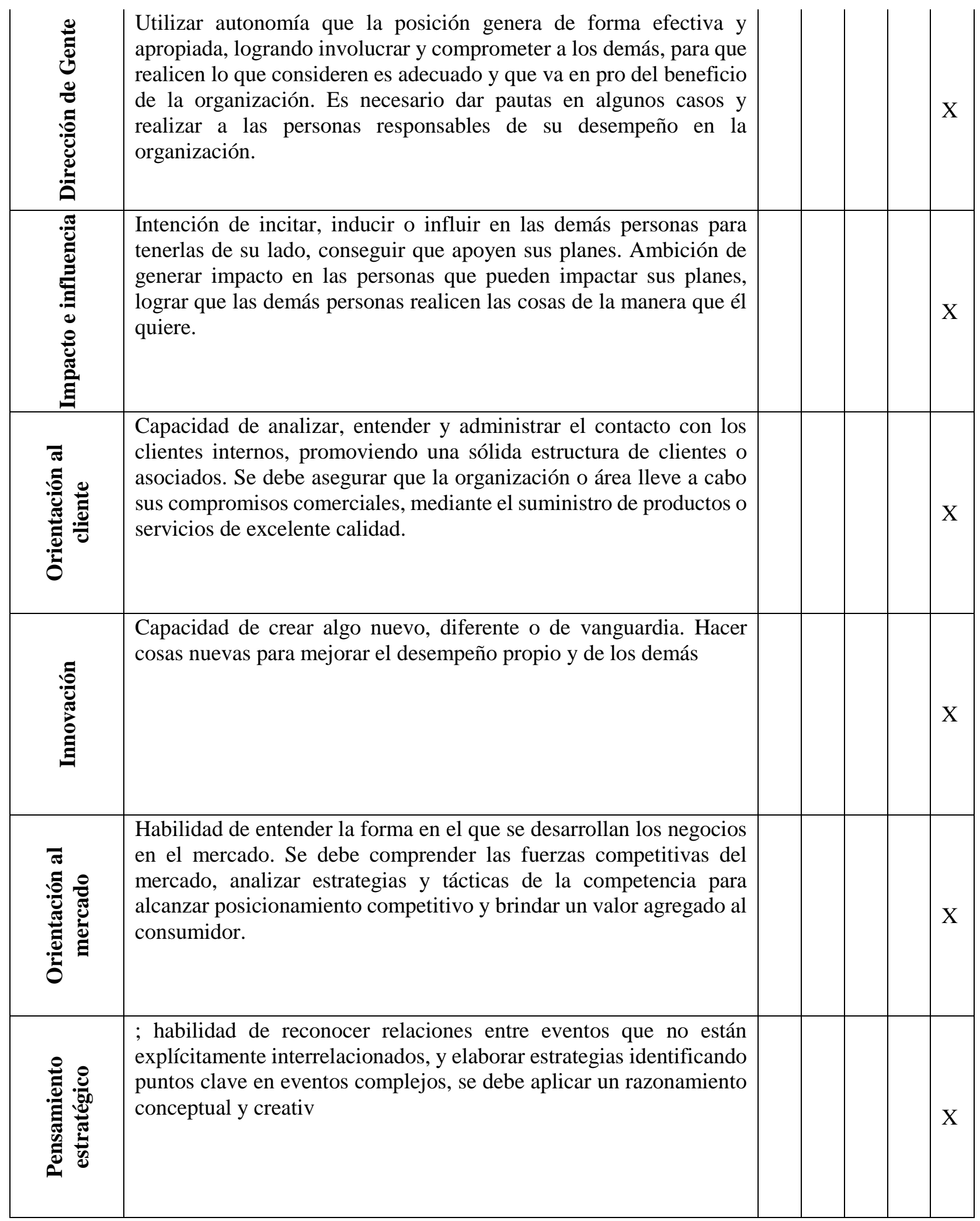




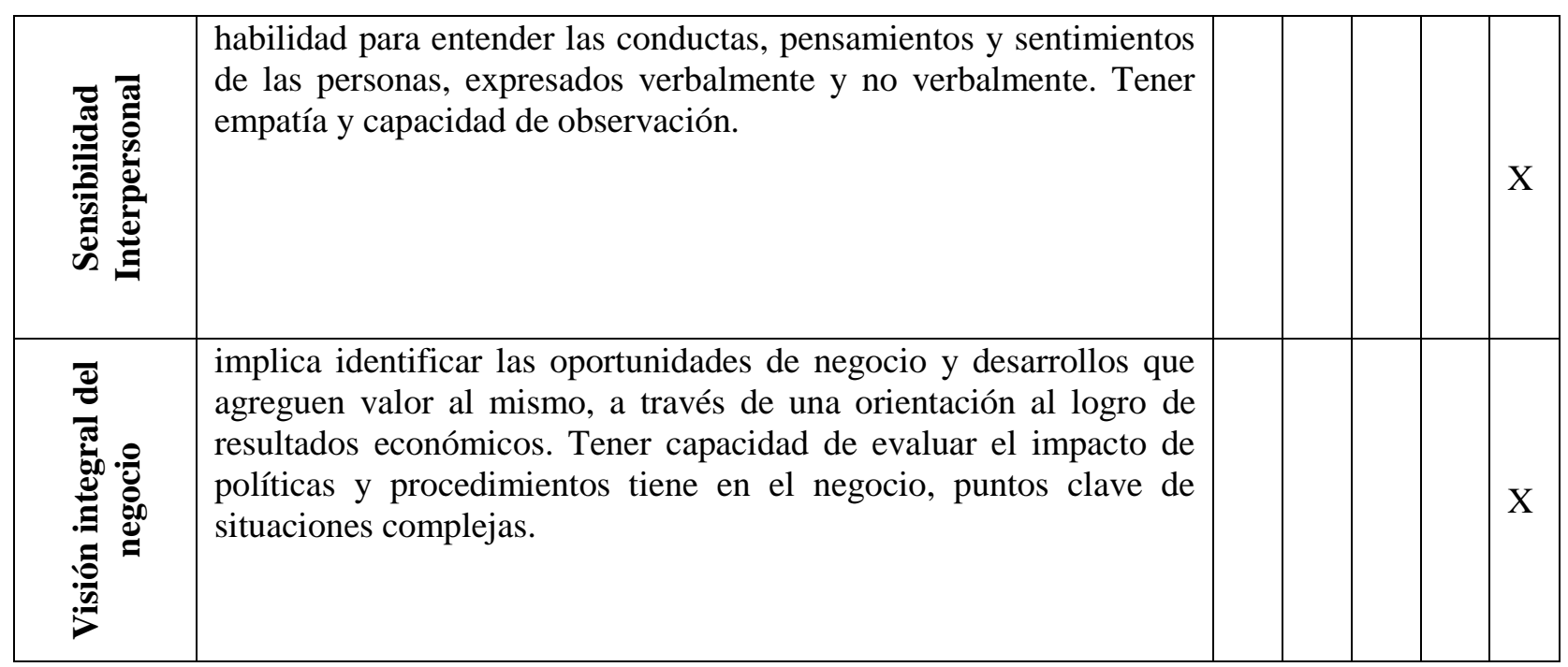




\section{Perfil de Puesto: Director de Desarrollo de Negocios}

\begin{tabular}{|c|c|c|}
\hline Área: & \multicolumn{2}{|l|}{ Dirección Desarrollo de Negocios } \\
\hline Cargo Jefe Área: & \multicolumn{2}{|l|}{ Director Desarrollo de Negocios } \\
\hline \# de personas a cargo & \multicolumn{2}{|l|}{1} \\
\hline Cargo al que reporta: & \multicolumn{2}{|l|}{ Gerente de País } \\
\hline Rol del cargo: & estratégico & soporte \\
\hline
\end{tabular}

\section{Misión de Cargo:}

Establecer y desarrollar la planeación estratégica del área comercial, acorde con las proyecciones, metas, retos y necesidades en el corto y mediano plazo, haciéndola sostenible en el tiempo.

\section{Responsabilidades del Cargo:}

\section{Responsabilidades}

1. Establecer estrategias de penetración y posicionamiento que permitan desarrollar la compañía especialmente en Colombia, respondiendo integralmente por la gestión comercial.

2. Diseñar, establecer y desarrollar estrategias comerciales.

3. la búsqueda y desarrollo de nuevas oportunidades de negocio, mantener contacto con cada uno de los clientes y buscar oportunidades de negocio.

4. Relación constante con la Dirección de operaciones para manejar el delivery de cada proceso.

\section{Requerimientos Educativos y de Formación:}

EDUCACION:

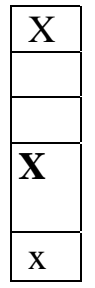

Bachillerato

Tecnologías

Universitario

Postgrados
Estudio técnico posterior a secundaria
DESCRIPCION:

\begin{tabular}{|c|}
\hline Bachiller \\
\hline \\
\hline Administración de empresas, Psicología, Ingeniería \\
Industrial \\
\hline Especialización en Administración de Empresas \\
\hline
\end{tabular}

\section{FORMACION:}

HABILIDADES: Impecable presentación personal, alta capacidad de expresión escrita, redacción, alta y facilidad de expresión oral, manejo de clientes, habilidad y dominio de la planeación estratégica anual.

EXPERIENCIA: Preferiblemente 2 años Liderando la estrategia de los procesos de búsqueda y selección de ejecutivos, relación a todos los niveles con el cliente, 3 años de experiencia en ejecución de procesos 


\section{Perfil de Competencias}

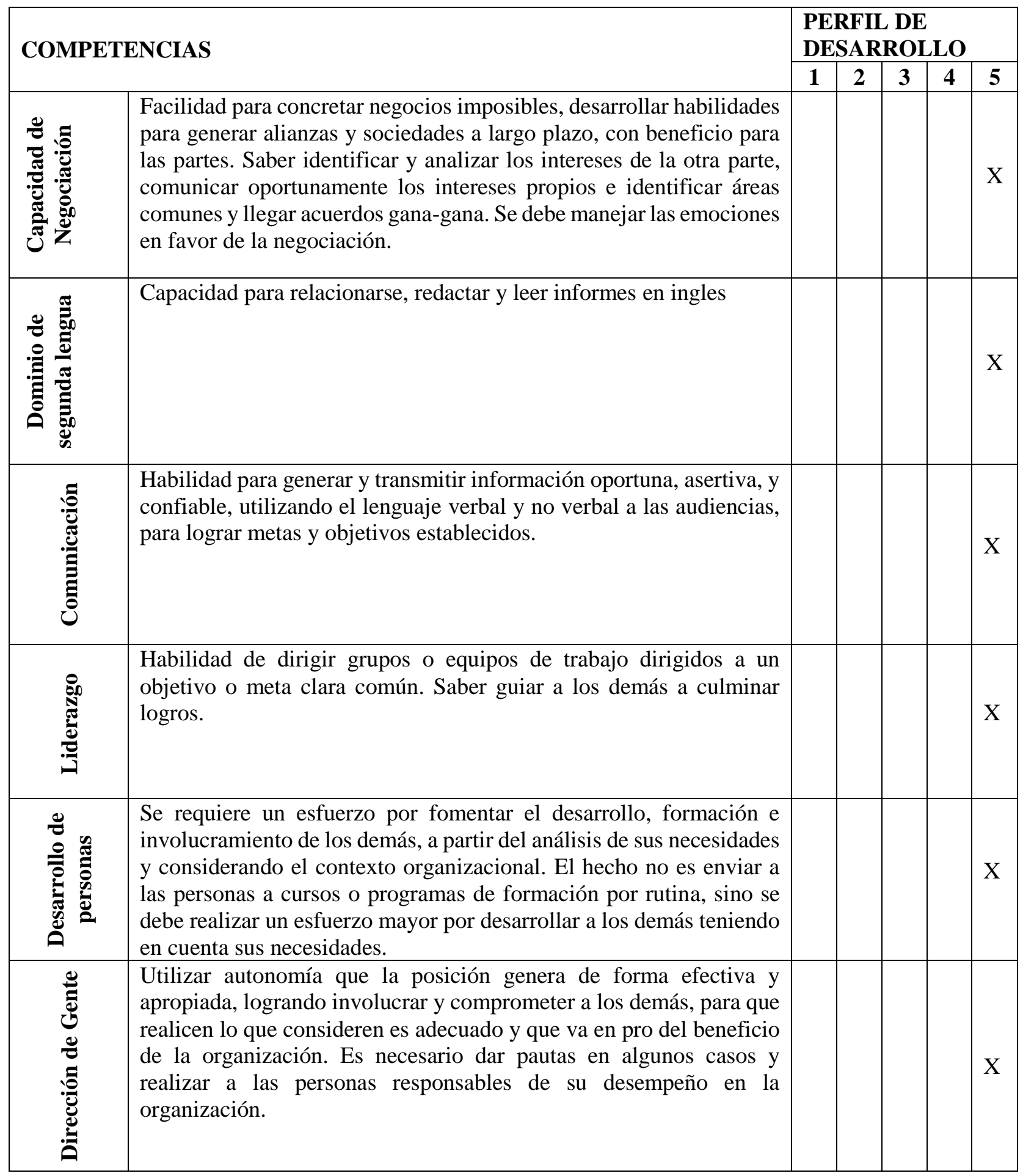




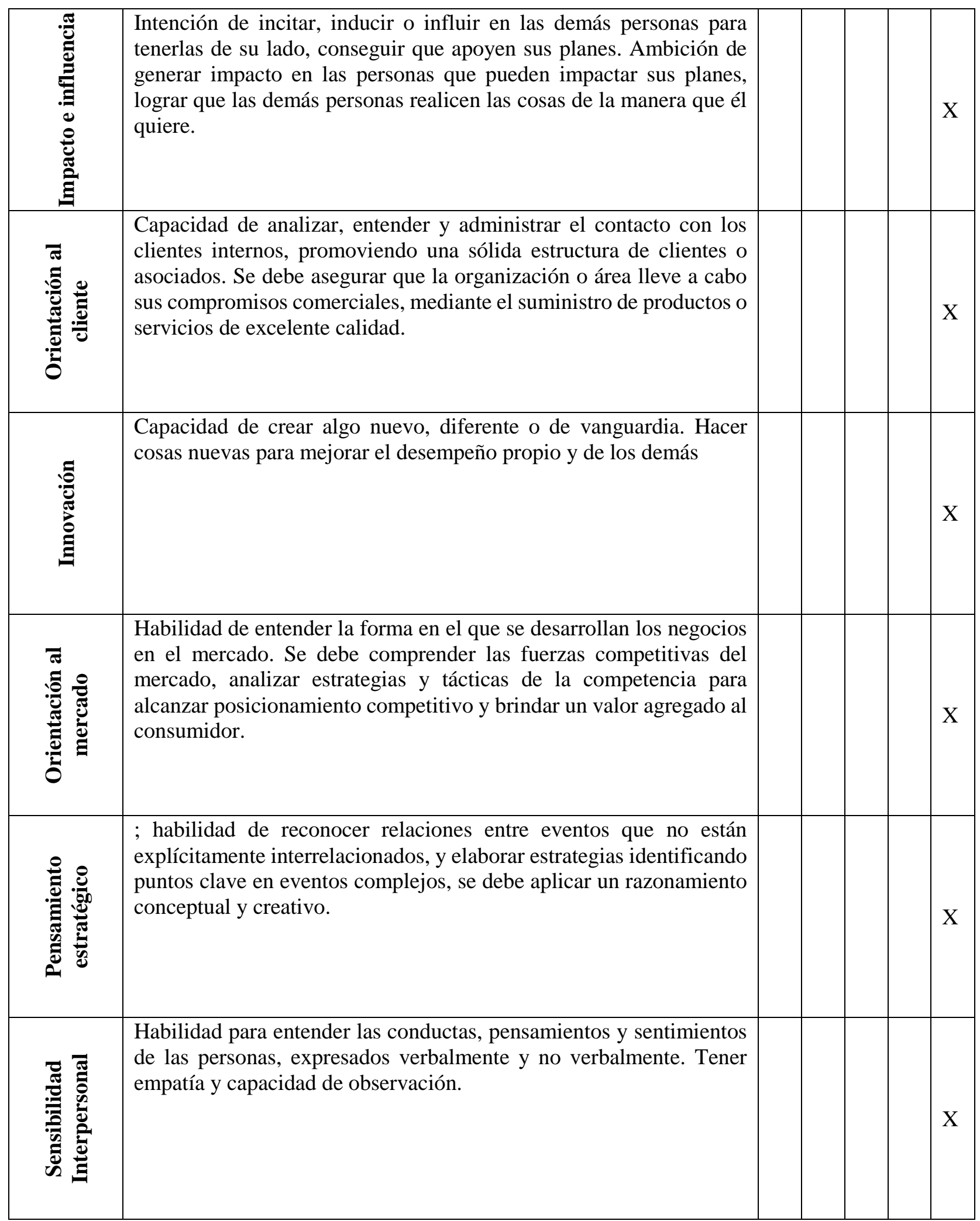




\begin{tabular}{|l|l|l|l|l|l|}
\hline & $\begin{array}{l}\text { implica identificar las oportunidades de negocio y desarrollos que } \\
\text { agreguen valor al mismo, a través de una orientación al logro de } \\
\text { resultados económicos. Tener capacidad de evaluar el impacto de } \\
\text { políticas y procedimientos tiene en el negocio, puntos clave de } \\
\text { situaciones complejas. }\end{array}$ & & & & \\
& & $X$ \\
\hline
\end{tabular}


Evaluaciones de Desempeñó

\begin{tabular}{|l|l|l|l|}
\hline \multicolumn{3}{|c|}{ EVALUACIÓN DE DESEMPEÑO - CONFIDENCIAL (Asistente de Investigación) } \\
\hline Nombre & Asistente de Investigación I & Edad & \\
\hline Reporte & Consultor Semi Senior & $\begin{array}{l}\text { Estudios } \\
\text { Formales }\end{array}$ & $\begin{array}{l}\text { Pregrado en } \\
\text { Administración de } \\
\text { Empresas }\end{array}$ \\
\hline Años de antiguiedad & & \multicolumn{2}{|l|}{} \\
\hline Periodo evaluado & $2017-2$ & Fecha \\
\hline
\end{tabular}




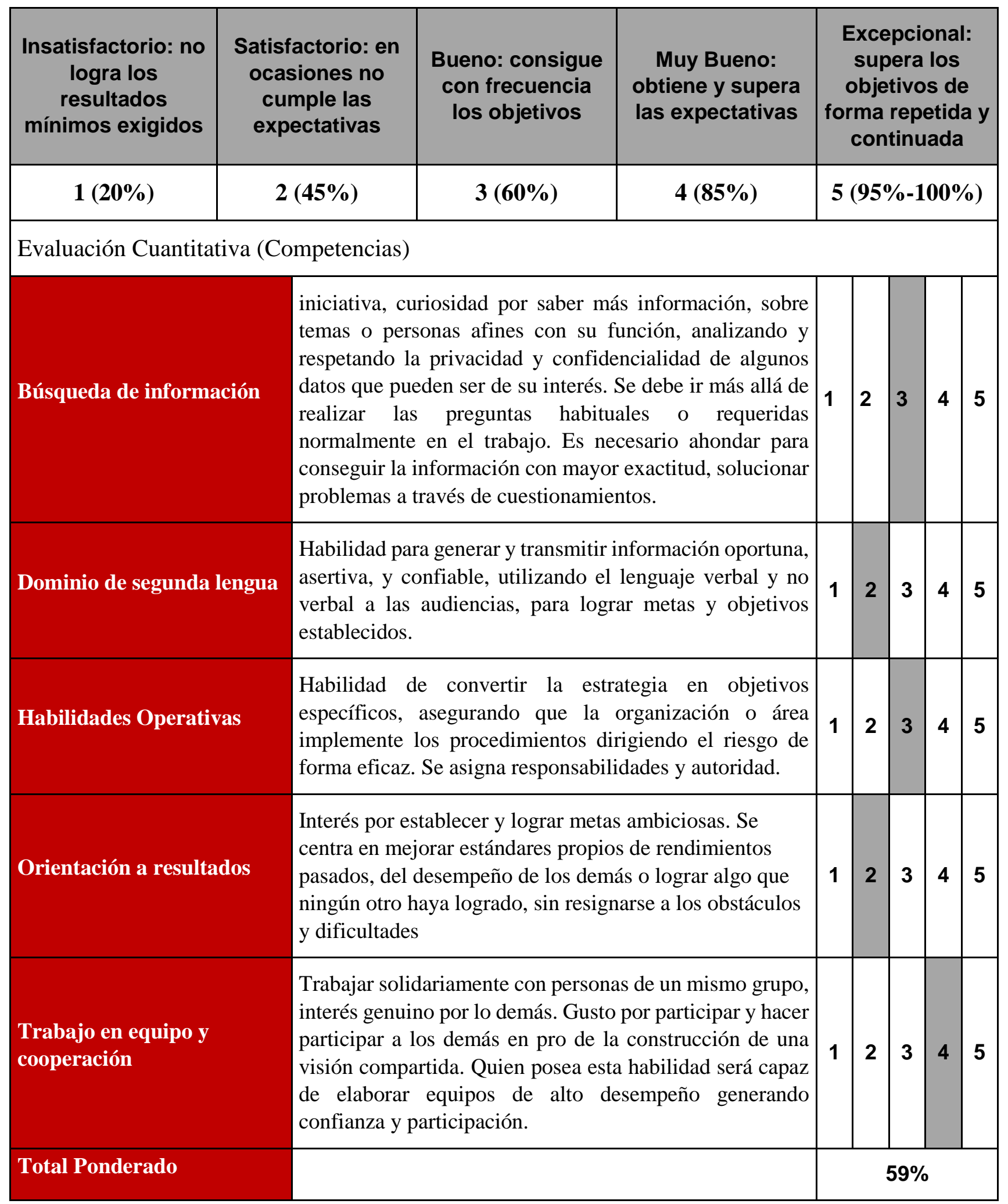




\begin{tabular}{|c|c|c|c|}
\hline \multicolumn{4}{|c|}{ EVALUACIÓN DE DESEMPEÑO - CONFIDENCIAL } \\
\hline Nombre & Asistente de Investigación II & Edad & \\
\hline Reporte & Consultor Semi Senior & $\begin{array}{l}\text { Estudios } \\
\text { Formales }\end{array}$ & Pregrado en Psicología \\
\hline Años de antigüedad & \multicolumn{3}{|l|}{1 año } \\
\hline Periodo evaluado & $2017-2$ & Fecha & $16 / 11 / 2017$ \\
\hline Comentarios & \multicolumn{3}{|c|}{$\begin{array}{l}\text { - Es un talento por desarrollar. } \\
\text { - Debe aprender a priorizar sus actividades del día a día para potencializar } \\
\text { sus resultados. } \\
\text { - Buen integrante de equipo. }\end{array}$} \\
\hline
\end{tabular}




\begin{tabular}{|c|c|c|c|c|c|c|c|c|c|}
\hline $\begin{array}{l}\text { Insatisfactorio: no } \\
\text { logra los } \\
\text { resultados } \\
\text { mínimos exigidos }\end{array}$ & \multicolumn{2}{|c|}{$\begin{array}{l}\text { Satisfactorio: en } \\
\text { ocasiones no } \\
\text { cumple las } \\
\text { expectativas }\end{array}$} & $\begin{array}{l}\text { Bueno: consigue } \\
\text { con frecuencia } \\
\text { los objetivos }\end{array}$ & $\begin{array}{l}\text { Muy Bueno: } \\
\text { obtiene y supera } \\
\text { las expectativas }\end{array}$ & \multicolumn{5}{|c|}{$\begin{array}{l}\text { Excepcional: } \\
\text { supera los } \\
\text { objetivos de } \\
\text { forma repetida y } \\
\text { continuada }\end{array}$} \\
\hline $1(20 \%)$ & & $(45 \%)$ & $3(60 \%)$ & $4(85 \%)$ & \multicolumn{5}{|c|}{$5(95 \%-100 \%)$} \\
\hline \multicolumn{10}{|c|}{ Evaluación Cuantitativa (Competencias) } \\
\hline \multicolumn{2}{|c|}{ Búsqueda de información } & \multicolumn{3}{|c|}{$\begin{array}{l}\text { iniciativa, curiosidad por saber más información, sobre } \\
\text { temas o personas afines con su función, analizando y } \\
\text { respetando la privacidad y confidencialidad de algunos } \\
\text { datos que pueden ser de su interés. Se debe ir más allá de } \\
\text { realizar las preguntas habituales o requeridas } \\
\text { normalmente en el trabajo. Es necesario ahondar para } \\
\text { conseguir la información con mayor exactitud, solucionar } \\
\text { problemas a través de cuestionamientos. }\end{array}$} & 1 & 2 & 3 & 4 & 5 \\
\hline \multicolumn{2}{|c|}{ Dominio de segunda lengua } & \multicolumn{3}{|c|}{$\begin{array}{l}\text { Habilidad para generar y transmitir información oportuna, } \\
\text { asertiva, y confiable, utilizando el lenguaje verbal y no } \\
\text { verbal a las audiencias, para lograr metas y objetivos } \\
\text { establecidos. }\end{array}$} & 1 & 2 & 3 & 4 & 5 \\
\hline \multicolumn{2}{|c|}{ Habilidades Operativas } & \multicolumn{3}{|c|}{$\begin{array}{l}\text { Habilidad de convertir la estrategia en objetivos } \\
\text { específicos, asegurando que la organización o área } \\
\text { implemente los procedimientos dirigiendo el riesgo de } \\
\text { forma eficaz. Se asigna responsabilidades y autoridad. }\end{array}$} & 1 & 2 & 3 & 4 & 5 \\
\hline \multicolumn{2}{|c|}{ Orientación a resultados } & \multicolumn{3}{|c|}{$\begin{array}{l}\text { Interés por establecer y lograr metas ambiciosas. Se } \\
\text { centra en mejorar estándares propios de rendimientos } \\
\text { pasados, del desempeño de los demás o lograr algo que } \\
\text { ningún otro haya logrado, sin resignarse a los obstáculos } \\
\text { y dificultades }\end{array}$} & 1 & 2 & 3 & 4 & 5 \\
\hline \multicolumn{2}{|l|}{$\begin{array}{l}\text { Trabajo en equipo y } \\
\text { cooperación }\end{array}$} & \multicolumn{3}{|c|}{$\begin{array}{l}\text { Trabajar solidariamente con personas de un mismo grupo, } \\
\text { interés genuino por lo demás. Gusto por participar y hacer } \\
\text { participar a los demás en pro de la construcción de una } \\
\text { visión compartida. Quien posea esta habilidad será capaz } \\
\text { de elaborar equipos de alto desempeño generando } \\
\text { confianza y participación. }\end{array}$} & 1 & 2 & 3 & 4 & 5 \\
\hline \multicolumn{5}{|l|}{ Total Ponderado } & \multicolumn{5}{|c|}{$71 \%$} \\
\hline
\end{tabular}




\begin{tabular}{|c|c|c|c|}
\hline \multicolumn{4}{|c|}{ EVALUACIÓN DE DESEMPEÑO - CONFIDENCIAL (Consultor Semi Senior) } \\
\hline Nombre & Consultor Semi Senior & Edad & \\
\hline Reporte & $\begin{array}{l}\text { Director Operaciones - Director de } \\
\text { Desarrollo de nuevos negocios }\end{array}$ & $\begin{array}{l}\text { Estudios } \\
\text { Formales }\end{array}$ & $\begin{array}{l}\text { Pregrado en } \\
\text { Administración de } \\
\text { Empresas }\end{array}$ \\
\hline \multicolumn{4}{|c|}{ Años de antigüedad } \\
\hline Periodo evaluado & $2017-2$ & Fecha & $16 / 11 / 2017$ \\
\hline Comentarios & \multicolumn{3}{|c|}{$\begin{array}{l}\text { - Debe trabajar en la confianza en sí misma, su trabajo } \\
\text { debe ser más consiente de ellos. } \\
\text { - Sabe trabajar en equipo, logra persuadir a su equipo. } \\
\text { - Genera valor en los proyectos asignados. }\end{array}$} \\
\hline
\end{tabular}




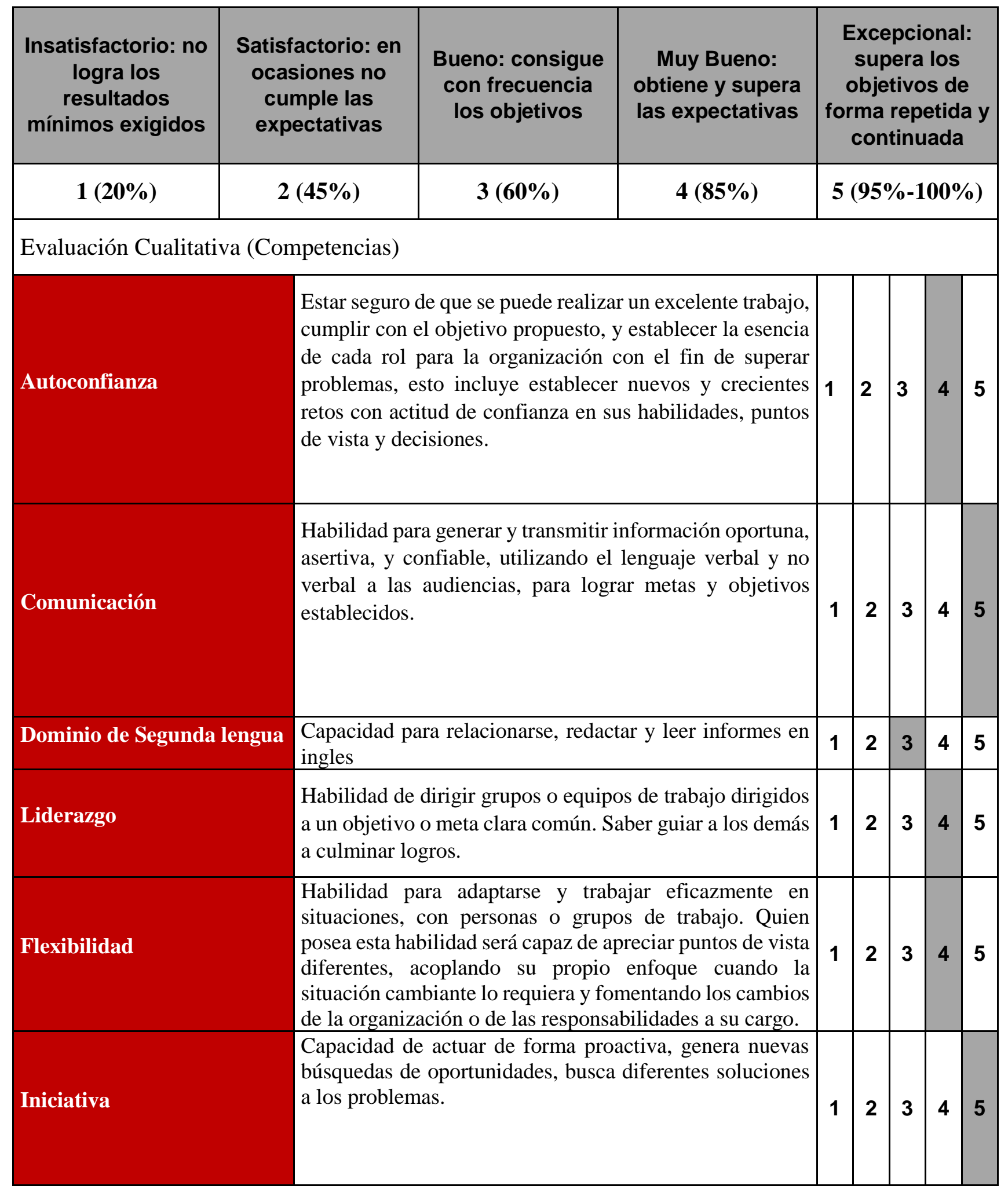




\begin{tabular}{|c|c|c|c|c|c|c|}
\hline Orientación a resultados & $\begin{array}{l}\text { Interés por establecer y lograr metas ambicionas. Se } \\
\text { centra en mejorar estándares propios de rendimientos } \\
\text { pasados, del desempeño de los demás o lograr algo que } \\
\text { ningún otro haya logrado, sin resignarse a los obstáculos } \\
\text { y dificultades. }\end{array}$ & 1 & 2 & 3 & 4 & 5 \\
\hline Orientación al cliente & $\begin{array}{l}\text { Capacidad de analizar, entender y administrar el contacto } \\
\text { con los clientes internos, promoviendo una sólida } \\
\text { estructura de clientes o asociados. Se debe asegurar que la } \\
\text { organización o área lleve a cabo sus compromisos } \\
\text { comerciales, mediante el suministro de productos o } \\
\text { servicios de excelente calidad. }\end{array}$ & 1 & 2 & 3 & 4 & 5 \\
\hline Resolución de problemas & $\begin{array}{l}\text { habilidad para identificar la información relevante, } \\
\text { generar conclusiones, evaluar impacto y toma de } \\
\text { decisiones basadas en las diferentes } \\
\text { establecidas. }\end{array}$ & 1 & 2 & 3 & 4 & 5 \\
\hline Total Ponderado & & \multicolumn{5}{|c|}{$85 \%$} \\
\hline
\end{tabular}




\begin{tabular}{|l|l|l|l|}
\hline \multicolumn{2}{|l|}{ EVALUACIÓN DE DESEMPENO - CONFIDENCIAL (Director de Desarrollo de Nuevos } \\
Negocios)
\end{tabular}




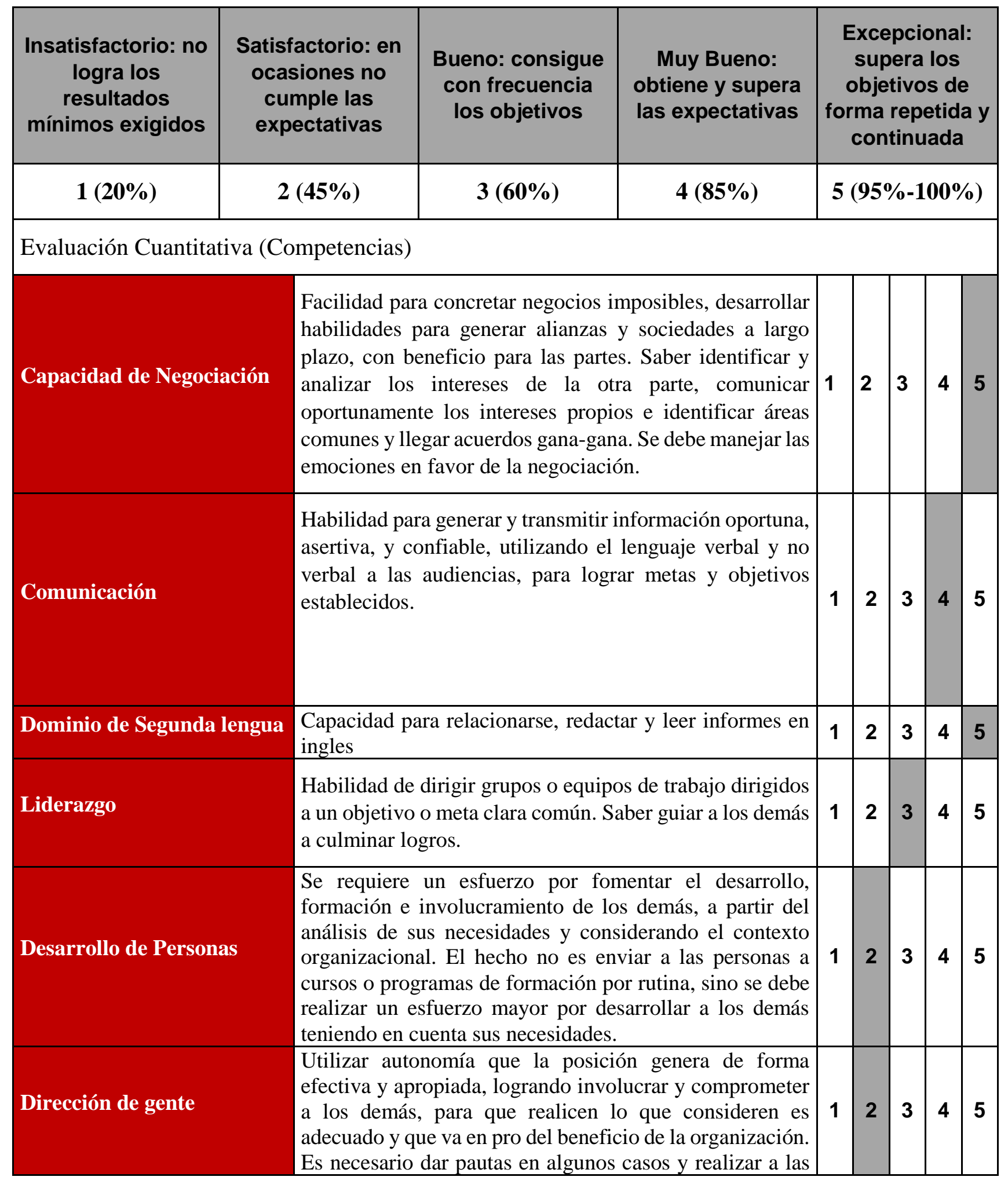




\begin{tabular}{|c|c|c|c|c|c|c|}
\hline & $\begin{array}{l}\text { personas responsables } \\
\text { organización. }\end{array}$ & & & & & \\
\hline Impacto e influencia & $\begin{array}{l}\text { Intención de incitar, inducir o influir en las demás } \\
\text { personas para tenerlas de su lado, conseguir que apoyen } \\
\text { sus planes. Ambición de generar impacto en las personas } \\
\text { que pueden impactar sus planes, lograr que las demás } \\
\text { personas realicen las cosas de la manera que él quiere. }\end{array}$ & 1 & 2 & 3 & 4 & 5 \\
\hline Orientación al cliente & $\begin{array}{l}\text { Capacidad de analizar, entender y administrar el contacto } \\
\text { con los clientes internos, promoviendo una sólida } \\
\text { estructura de clientes o asociados. Se debe asegurar que la } \\
\text { organización o área lleve a cabo sus compromisos } \\
\text { comerciales, mediante el suministro de productos o } \\
\text { servicios de excelente calidad. }\end{array}$ & 1 & 2 & 3 & 4 & 5 \\
\hline Innovación & $\begin{array}{l}\text { Capacidad de crear algo nuevo, diferente o de vanguardia. } \\
\text { Hacer cosas nuevas para mejorar el desempeño propio y } \\
\text { de los demás }\end{array}$ & 1 & 2 & 3 & 4 & 5 \\
\hline Orientación al mercado & $\begin{array}{l}\text { Habilidad de entender la forma en el que se desarrollan los } \\
\text { negocios en el mercado. Se debe comprender las fuerzas } \\
\text { competitivas del mercado, analizar estrategias y tácticas } \\
\text { de la competencia para alcanzar posicionamiento } \\
\text { competitivo y brindar un valor agregado al consumidor. }\end{array}$ & 1 & 2 & 3 & 4 & 5 \\
\hline Pensamiento estratégico & $\begin{array}{l}\text { Habilidad de reconocer relaciones entre eventos que no } \\
\text { están explícitamente interrelacionados, y elaborar } \\
\text { estrategias identificando puntos clave en eventos } \\
\text { complejos, se debe aplicar un razonamiento conceptual y } \\
\text { creativa. }\end{array}$ & 1 & 2 & 3 & 4 & 5 \\
\hline Sensibilidad Interpersonal & $\begin{array}{l}\text { Habilidad para entender las conductas, pensamientos y } \\
\text { sentimientos de las personas, expresados verbalmente y } \\
\text { no verbalmente. Tener empatía y capacidad de } \\
\text { observación. }\end{array}$ & 1 & 2 & 3 & 4 & 5 \\
\hline Visión integral del negocio & $\begin{array}{l}\text { Implica identificar las oportunidades de negocio y } \\
\text { desarrollos que agreguen valor al mismo, a través de una } \\
\text { orientación al logro de resultados económicos. Tener } \\
\text { capacidad de evaluar el impacto de políticas y } \\
\text { procedimientos tiene en el negocio, puntos clave de } \\
\text { situaciones complejas. }\end{array}$ & 1 & 2 & 3 & 4 & 5 \\
\hline Total ponderado & & \multicolumn{5}{|c|}{$67 \%$} \\
\hline
\end{tabular}




\begin{tabular}{|c|c|c|c|}
\hline \multicolumn{4}{|c|}{ EVALUACIÓN DE DESEMPEÑO - CONFIDENCIAL (Directora de Operaciones) } \\
\hline Nombre & Director de Operaciones & Edad & \\
\hline Reporte & Director de País & $\begin{array}{l}\text { Estudios } \\
\text { Formales }\end{array}$ & $\begin{array}{l}\text { Pregrado en Mercadeo } \\
\text { Programa de Alta } \\
\text { Dirección }\end{array}$ \\
\hline \multicolumn{4}{|c|}{ Años de antigïedad } \\
\hline Periodo evaluado & $2017-2$ & Fecha & $16 / 11 / 2017$ \\
\hline Comentarios & \multicolumn{3}{|c|}{$\begin{array}{l}\text { - Gran jugador de equipo, orientada a resultados y a personas, su manejo } \\
\text { de cliente y equipo es excelente, genera valor a la organización, } \\
\text { analítica y estratégica. }\end{array}$} \\
\hline
\end{tabular}




\begin{tabular}{|c|c|c|c|c|c|c|c|c|c|}
\hline $\begin{array}{l}\text { Insatisfactorio: no } \\
\text { logra los } \\
\text { resultados } \\
\text { mínimos exigidos }\end{array}$ & \multicolumn{2}{|c|}{$\begin{array}{l}\text { Satisfactorio: en } \\
\text { ocasiones no } \\
\text { cumple las } \\
\text { expectativas }\end{array}$} & $\begin{array}{l}\text { Bueno: consigue } \\
\text { con frecuencia } \\
\text { los objetivos }\end{array}$ & $\begin{array}{l}\text { Muy Bueno: } \\
\text { obtiene y supera } \\
\text { las expectativas }\end{array}$ & \multicolumn{5}{|c|}{$\begin{array}{l}\text { Excepcional: } \\
\text { supera los } \\
\text { objetivos de } \\
\text { forma repetida y } \\
\text { continuada }\end{array}$} \\
\hline $1(20 \%)$ & & $(45 \%)$ & $3(60 \%)$ & $4(85 \%)$ & \multicolumn{5}{|c|}{$5(95 \%-100 \%)$} \\
\hline \multicolumn{10}{|c|}{ Evaluación Cuantitativa (Competencias) } \\
\hline \multicolumn{2}{|c|}{ Capacidad de Negociación } & \multicolumn{3}{|c|}{$\begin{array}{l}\text { Facilidad para concretar negocios imposibles, desarrollar } \\
\text { habilidades para generar alianzas y sociedades a largo } \\
\text { plazo, con beneficio para las partes. Saber identificar y } \\
\text { analizar los intereses de la otra parte, comunicar } \\
\text { oportunamente los intereses propios e identificar áreas } \\
\text { comunes y llegar acuerdos gana-gana. Se debe manejar las } \\
\text { emociones en favor de la negociación. }\end{array}$} & 1 & 2 & 3 & 4 & 5 \\
\hline Comunicación & & \multicolumn{3}{|c|}{$\begin{array}{l}\text { Habilidad para generar y transmitir información oportuna, } \\
\text { asertiva, y confiable, utilizando el lenguaje verbal y no } \\
\text { verbal a las audiencias, para lograr metas y objetivos } \\
\text { establecidos. }\end{array}$} & 1 & 2 & 3 & 4 & 5 \\
\hline \multicolumn{2}{|c|}{ Dominio de Segunda lengua } & \multicolumn{3}{|c|}{$\begin{array}{l}\text { Capacidad para relacionarse, redactar y leer informes en } \\
\text { ingles }\end{array}$} & 1 & 2 & 3 & 4 & 5 \\
\hline \multicolumn{2}{|l|}{ Liderazgo } & \multicolumn{3}{|c|}{$\begin{array}{l}\text { Habilidad de dirigir grupos o equipos de trabajo dirigidos } \\
\text { a un objetivo o meta clara común. Saber guiar a los demás } \\
\text { a culminar logros. }\end{array}$} & 1 & 2 & 3 & 4 & 5 \\
\hline \multicolumn{2}{|l|}{ Desarrollo de Personas } & \multicolumn{3}{|c|}{$\begin{array}{l}\text { Se requiere un esfuerzo por fomentar el desarrollo, } \\
\text { formación e involucramiento de los demás, a partir del } \\
\text { análisis de sus necesidades y considerando el contexto } \\
\text { organizacional. El hecho no es enviar a las personas a } \\
\text { cursos o programas de formación por rutina, sino se debe } \\
\text { realizar un esfuerzo mayor por desarrollar a los demás } \\
\text { teniendo en cuenta sus necesidades. }\end{array}$} & 1 & 2 & 3 & 4 & 5 \\
\hline \multicolumn{2}{|l|}{ Dirección de gente } & \multicolumn{3}{|c|}{$\begin{array}{l}\text { Utilizar autonomía que la posición genera de forma } \\
\text { efectiva y apropiada, logrando involucrar y comprometer } \\
\text { a los demás, para que realicen lo que consideren es } \\
\text { adecuado y que va en pro del beneficio de la organización. } \\
\text { Es necesario dar pautas en algunos casos y realizar a las }\end{array}$} & 1 & 2 & 3 & 4 & 5 \\
\hline
\end{tabular}




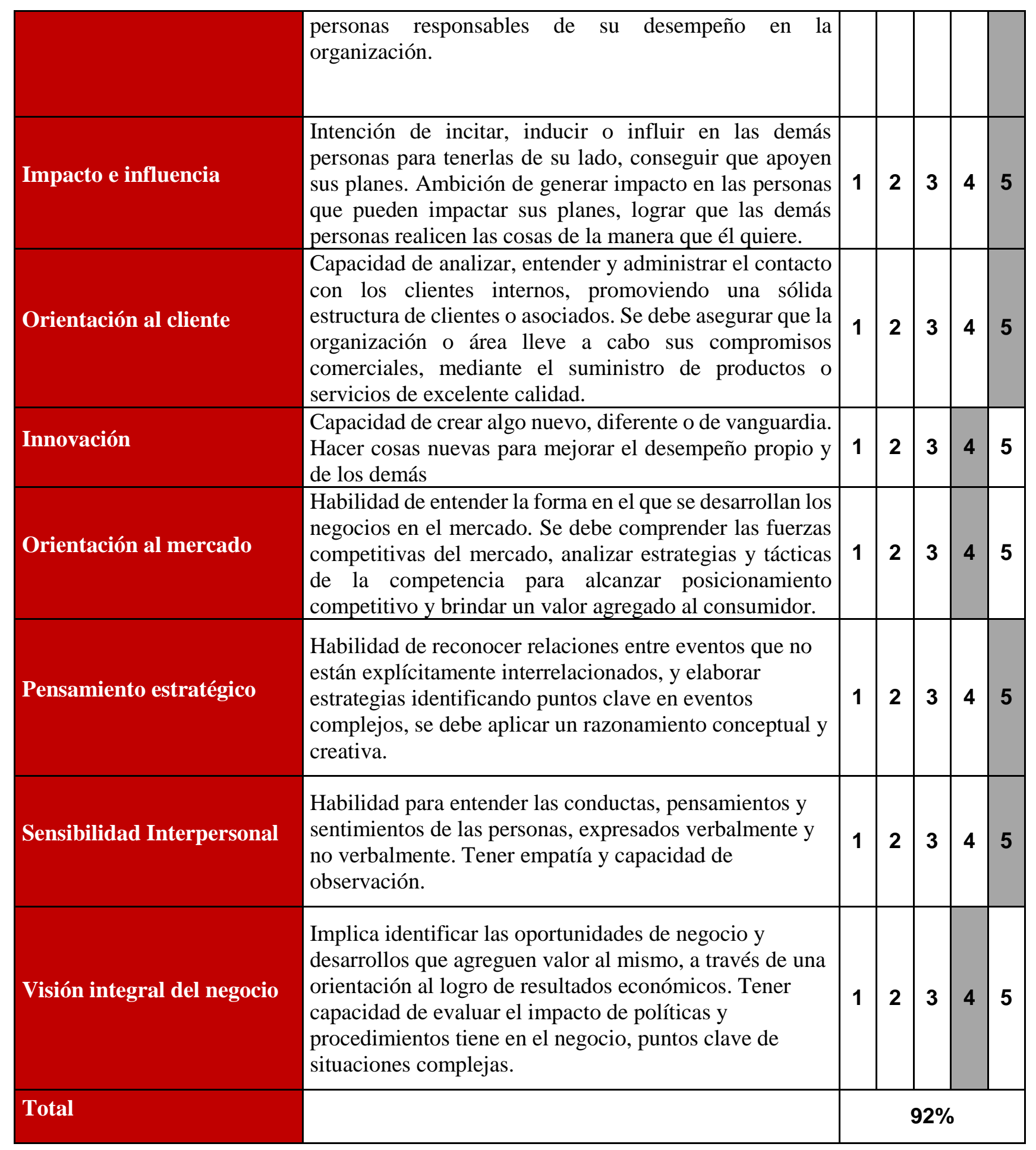




\section{MODELO PLAN DE DESARROLLO PERSONA CLAVE - Directora de operaciones}

Un plan de desarrollo comprende un conjunto de medidas orientadas a soportar un proceso de cambio a partir de la identificación de competencias que impactan el desempeño del ejecutivo y la efectividad en su liderazgo.

En este documento encontrará un resumen de sus áreas de desarrollo, apalancadores y facilitadores de competencias debidamente definidos, y unas acciones de mejora tendientes a desarrollar las brechas identificadas a lo largo del proceso de evaluación.

\section{$\underline{\text { Áreas de Desarrollo }}$}

Las áreas de desarrollo son aquellas áreas identificadas como críticas o en un bajo nivel de desarrollo, que de una u otra forma impactan su gestión en el día a día, y la efectividad del liderazgo.

Visión integral de negocio

$>$ Orientación al mercado

$>$ Innovación

\section{Visión integral del negocio}

Implica identificar las oportunidades de negocio y desarrollos que agreguen valor al mismo, a través de una orientación al logro de resultados económicos. Tener capacidad de evaluar el impacto de políticas y procedimientos tiene en el negocio, puntos clave de situaciones complejas.

\section{Orientación al mercado}

Habilidad de entender la forma en el que se desarrollan los negocios en el mercado. Se debe comprender las fuerzas competitivas del mercado, analizar estrategias y tácticas de la competencia para alcanzar posicionamiento competitivo y brindar un valor agregado al consumidor.

\section{Innovación}

Capacidad de crear algo nuevo, diferente o de vanguardia. Hacer cosas nuevas para mejorar el desempeño propio y de los demás

\section{Apalanca dores del desarrollo}

Los apalancadores son aquellas características consideradas fortalezas, que permiten movilizar y gestionar las áreas de desarrollo que fueron identificadas. 
$>$ Pensamiento estratégico

$>$ Orientación al cliente

$>$ Impacto e influencia

\section{Pensamiento estratégico}

Habilidad de reconocer relaciones entre eventos que no están explícitamente interrelacionados, y elaborar estrategias identificando puntos clave en eventos complejos, se debe aplicar un razonamiento conceptual y creativa.

\section{Orientación al cliente}

Capacidad de analizar, entender y administrar el contacto con los clientes internos, promoviendo una sólida estructura de clientes o asociados. Se debe asegurar que la organización o área lleve a cabo sus compromisos comerciales, mediante el suministro de productos o servicios de excelente calidad.

\section{Impacto e influencia}

Intención de incitar, inducir o influir en las demás personas para tenerlas de su lado, conseguir que apoyen sus planes. Ambición de generar impacto en las personas que pueden impactar sus planes, lograr que las demás personas realicen las cosas de la manera que él quiere.

\section{$\underline{\text { Facilitadores del Desempeño }}$}

Los facilitadores de desempeño son aquellos espacios y ambientes donde el Director de Operaciones puede desplegar todo su potencial.

- Donde se pone énfasis en el análisis y resolución de problemas y se valora realmente la capacidad para resolver problemas.

- Donde se valora la capacidad de llegar con rapidez a lo relevante.

- Donde se fomenta el desarrollo de teorías y conceptos.

- Donde se valora ser emprendedor y se pone énfasis en identificar oportunidades de negocio.

- Donde hay una fuerte orientación estratégica.

- Donde se pone énfasis en el resultado y la determinación para triunfar y se recompensa a las personas por obtener resultados extraordinarios.

- Donde hay oportunidades para asumir responsabilidades de liderazgo y existe control sobre personas y recursos. 


\section{Potencializar competencia}

Visión integral del negocio, Orientación al mercado, innovación

\section{Estrategias básicas}

Asista a principales eventos de RRHH para relacionarse con personas claves del mercado.

$>$ Con el conocimiento de los diferentes clientes y la relación con los mismos analice las necesidades actuales de los competidores.

$>$ Apóyese en la información del corporativo para obtener información necesaria de las diferents variables de negocio.

$>$ Realice sesiones de Design thinkig y Brain storming con su equipo.

$>$ Evalúe nuevos modelos de negocio.

\section{RECOMENDACIONES DEL PLAN DE CARRERA}

Dentro del proceso de evaluación de desempeño, orientado a fortalecer el autoconocimiento a partir de la identificación de competencias, se visualizaron fortalezas importantes además de los apalancadores mencionados anteriormente.

Para el Director de Operaciones es importante tener cambios y desafíos permanentes donde pueda poner sus altos niveles de energía, su carácter propositivo y de iniciativas constantes, así como su alta orientación al resultado.

Se siente cómoda en escenarios que impliquen liderar y desarrollar a otros, a través de un liderazgo que inspira, motiva y anima a otros a ser la mejor versión de sí mismos. Es una profesional que hace que las cosas pasen, usando su iniciativa y energía para superar cada obstáculo que se le presenta. Muestra impaciencia por iniciar los trabajos y asumir nuevos retos, motivada altamente por el cambio.

En el proceso de toma de decisiones se percibe un enfoque pragmático, soportado en información medible y cuantificable y en un proceso de análisis juicioso y riguroso.

Denota grandes fortalezas en su capacidad para generar ideas que traigan consigo nuevas y mejores formas de hacer las cosas, así como su habilidad para explorar posibilidades, plantear soluciones innovadoras y generar estrategias que atiendan a las necesidades de mediano y largo plazo de las organizaciones. 